\title{
Role of Streptococcus pneumoniae Proteins in Evasion of Complement-Mediated Immunity
}

\author{
Greiciely O. Andre', Thiago R. Converso ${ }^{2,3}$, Walter R. Politano', Lucio F. C. Ferraz', \\ Marcelo L. Ribeiro ${ }^{4}$, Luciana C. C. Leite ${ }^{2}$ and Michelle Darrieux ${ }^{1 *}$ \\ ${ }^{1}$ Laboratório de Biologia Celular e Molecular de Microrganismos, Universidade São Francisco, Bragança Paulista, Brazil, \\ ${ }^{2}$ Centro de Biotecnologia, Instituto Butantan, São Paulo, Brazil, ${ }^{3}$ Programa de Pós-graduação Interunidades em \\ Biotecnologia, Universidade de São Paulo, São Paulo, Brazil, ${ }^{4}$ Laboratório de Farmacologia, Universidade São Francisco, \\ Bragança Paulista, Brazil
}

The complement system plays a central role in immune defense against Streptococcus pneumoniae. In order to evade complement attack, pneumococci have evolved a number of mechanisms that limit complement mediated opsonization and subsequent phagocytosis. This review focuses on the strategies employed by pneumococci to circumvent complement mediated immunity, both in vitro and in vivo. At last, since many of the proteins involved in interactions with complement components are vaccine candidates in different stages of validation, we explore the use of these antigens alone or in combination, as potential vaccine approaches that aim at elimination or drastic reduction in the ability of this bacterium to evade complement.

Keywords: complement system, Streptococcus pneumoniae, virulence factors pneumococcal surface proteins, pneumococcal moonlighting proteins, protein-based vaccines

\section{INTRODUCTION}

The complement system is an important mechanism in human immunity, with more than thirty proteins produced in soluble phase by the liver or expressed in cell surfaces [reviewed in (Ritchie et al., 2002; Dunkelberger and Song, 2010; Merle et al., 2015a)]. This system comprises a set of recognition molecules present in the plasma and interstitial fluids that are quickly activated in response to pathogens such as bacteria, yeast and virus, as well as infected cells and damaged tissues (Dunkelberger and Song, 2010; Ehrnthaller et al., 2011). Complement activation is triggered by serine protease domains present in components that become active and cleave the next protein in a cascade-like manner [reviewed in (Ehrnthaller et al., 2011; Merle et al., 2015a)]. The proteolytic cleavage steps generate fragments that bind to the microbial surfaces thereby acting as opsonins, promoting a more efficient phagocytosis and releasing peptides into the bloodstream, which are able to induce inflammatory responses [reviewed in (Merle et al., 2015b)]. Complement activation also promotes assembly of the membrane attack complex (MAC), which is capable of forming pores on membranes, causing osmotic lysis (Esser, 1994; Ritchie et al., 2002).

Streptococcus pneumoniae is a common colonizer of the human nasopharynx and is usually asymptomatic; however, in susceptible hosts it can invade other niches, causing otitis media, conjunctivitis, pneumonia, meningitis, and septicaemia (Kadioglu et al., 2008). The immune response against pneumococcal infections is highly supported by complement activities such as opsonization and activation of inflammatory responses (Janoff et al., 1999; Jarva et al., 2003). In order to evade the anti-bacterial effects of complement, pneumococci have developed many 
virulence factors that impair complement activity, thus contributing to bacterial evasion from the immune system (Jarva et al., 2003).

The current prophylaxis against pneumococcal diseases is based on polysaccharide vaccines (alone or conjugated to protein carriers), which have proven to be effective against invasive disease (Braido et al., 2008). However, high production costs and a reduced number of polysaccharide serotypes included in the formulations (a limitation of the conjugation process) have hampered the implementation of these vaccines in lower income countries, which are greatly affected by pneumococcal diseases (Croney et al., 2013). This scenario encourages the efforts to find alternative vaccines that can offer higher coverage at a reduced cost, as well as increasing protection against noninvasive disease (Moffitt and Malley, 2011; Darrieux et al., 2015). Based on these considerations and the role of bacterial proteins in complement attack, many proteins have been evaluated as vaccines in animal infection models, with encouraging outcomes. The employment of proteins that have roles in the inhibition of complement as vaccine antigens could promote the blockage of anti-complement abilities of pneumococci and result in more effective opsonophagocytosis. In addition, the combination of proteins may trigger broader, more effective immune responses compared to the use of one antigen alone. Therefore, the present review discusses the role of pneumococcal proteins in complement evasion, as well as the potential of using combinations of these proteins as pneumococcal vaccines.

\section{CONTRIBUTION OF THE COMPLEMENT SYSTEM TO HOST IMMUNITY AGAINST PNEUMOCOCCI}

As a classic extracellular bacterium, antibody-enhanced complement-mediated phagocytosis is an essential mechanism of pneumococcal clearance from the host (Brown et al., 1983; Paterson and Orihuela, 2010). Infection with S. pneumoniae activates all three pathways of the Complement System (Figure 1A), which converge in the formation of $\mathrm{C} 3 \mathrm{~b}$ and generate other molecules involved in opsonophagocytosis and activation of inflammatory responses (Supplementary Table 1).

The classical pathway is activated by specific antibodies and by recognition of cell wall phosphorylcholine by natural IgM (Brown et al., 2002). In the absence of antibodies, SIGN$\mathrm{R} 1$, a transmembrane C-type lectin expressed by macrophages, recognizes carbohydrates on the pneumococcal surface and binds to C1q (Kang et al., 2006). Moreover, polymeric IgA molecules can activate complement on the pneumococcal surface (Janoff et al., 1999). More recently, it has been demonstrated that C1q acts as a bridge between pneumococci and host tissues in vitro. $\mathrm{Clq}$ bound to pneumococcal surface proteins through its C-terminal globular head region, in an antibody-independent fashion. Furthermore, C1q bound to pneumococci was able to interact with respiratory cells (Agarwal et al., 2013a) possibly through glycosaminoglycan receptors (GAG) on their surface (Almeda et al., 1983) - promoting bacterial adherence and invasion (Agarwal et al., 2013a). The consequences of this interaction have not been investigated in vivo, although $\mathrm{C} 1 \mathrm{q}$ bound simultaneously to pneumococci and host cells is still able to promote complement activation on pneumococcal cells (Agarwal et al., 2013a).

After recognition, the $\mathrm{C} 1$ complex becomes active and cleaves $\mathrm{C} 4$ into $\mathrm{C} 4 \mathrm{a}$ - released to the soluble phase - and $\mathrm{C} 4 \mathrm{~b}$, which remains attached to the bacterial surface; $\mathrm{C} 2$ binds to $\mathrm{C} 4 \mathrm{~b}$ and is split up by $\mathrm{C} 1$ s yielding $\mathrm{C} 2 \mathrm{a}$ - that remains bound to $\mathrm{C} 4 \mathrm{~b}$ - and $\mathrm{C} 2 \mathrm{~b}$. The C4b2a, termed C3 convertase of the classical pathway, is able to cleave plasmatic C3 into C3a (anaphylatoxin) and C3b. $\mathrm{C} 3 \mathrm{~b}$ plays a pivotal role in the complement system; it is required to form the $\mathrm{C} 5$ convertase complex, when additional C3b binds to C3 convertase [reviewed in (Ehrnthaller et al., 2011; Merle et al., 2015a)]. Formation of C5 convertase marks the late stage of complement activation, which culminates with the assembly of MAC [reviewed in (Esser, 1994; Ehrnthaller et al., 2011)]. As a Gram-positive pathogen, the thick peptidoglycan layer on the pneumococcal cell wall limits the effects of MAC attack (Jarva et al., 2003); yet, the complement opsonic and pro-inflammatory functions are essential for the control of pneumococcal infections (Brown et al., 1983; Paterson and Mitchell, 2006), facilitating bacterial phagocytosis and clearance. In that matter, $\mathrm{C} 3 \mathrm{~b}$ attached to microbial surfaces may act as an opsonin, or generate the amplification loop, where $\mathrm{C} 3 \mathrm{~b}$ associates with $\mathrm{Bb}$, a protein of alternative pathway, promoting more C3 convertase formation [reviewed in (Ehrnthaller et al., 2011; Merle et al., 2015a)].

The importance of the classical pathway for immunity against pneumococci is further supported by the observation that deficiency in classical complement components such as C1q, C4 and C2 is associated with recurrent and severe pneumococcal infections (Rupprecht et al., 2007; Yuste et al., 2008). Similarly, mouse models of complement deficiency (either by genetic manipulation or transient depletion) reveal an increased susceptibility to pneumococcal sepsis (Brown et al., 2002).

The lectin pathway is initiated when Mannose-binding lectin (MBL), collectin-10, collectin-11, or ficolins-1, 2, or 3 bind to target surfaces and interact with the serine proteases MASP1, 2, and 3. Upon target binding, MASP-1 can self-activate and is required for activation of MASP-2. MASP-2 then cleaves $\mathrm{C} 4$ and both enzymes cleave $\mathrm{C} 2$, generating the classical C3 convertase $(\mathrm{C} 4 \mathrm{~b} 2 \mathrm{a})$. A third serine protease, MASP-3, is able to activate pro-Factor D [pro-FD) in the resting human blood, favoring alternative complement pathway activation [reviewed in (Dobo et al., 2016)]. The lectin pathway plays a less crucial but still important role in complement-mediated immunity against pneumococci (Ali et al., 2012; Garcia-Laorden et al., 2013). While a previous report found no clear role for MBL in pneumococcal infections (Brown et al., 2002), more recent studies found an important contribution for the lectin pathway in mice that do not express ficolins (Endo et al., 2012) or MASP-2 (Ali et al., 2012), which showed an increased susceptibility to pneumococcal infections and a reduced opsonizing capacity in non-immune hosts (Ali et al., 2012; Endo et al., 2012). Different components on the pneumococcal surface interact with lectins: L-ficolin binds to the capsular polysaccharides $11 \mathrm{~A}, 11 \mathrm{D}$, and $11 \mathrm{~F}$, and to phosphorylcholine residues (ChoP) on the bacterial cell wall, 


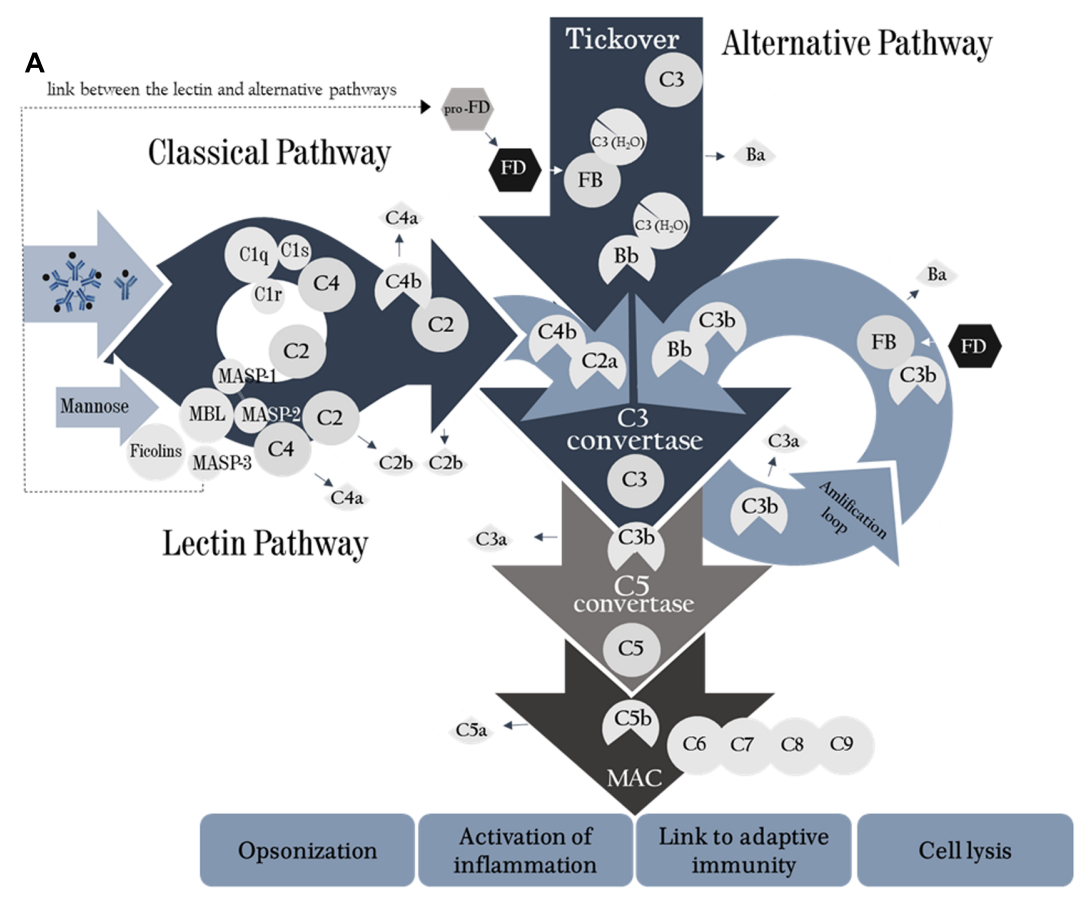

B

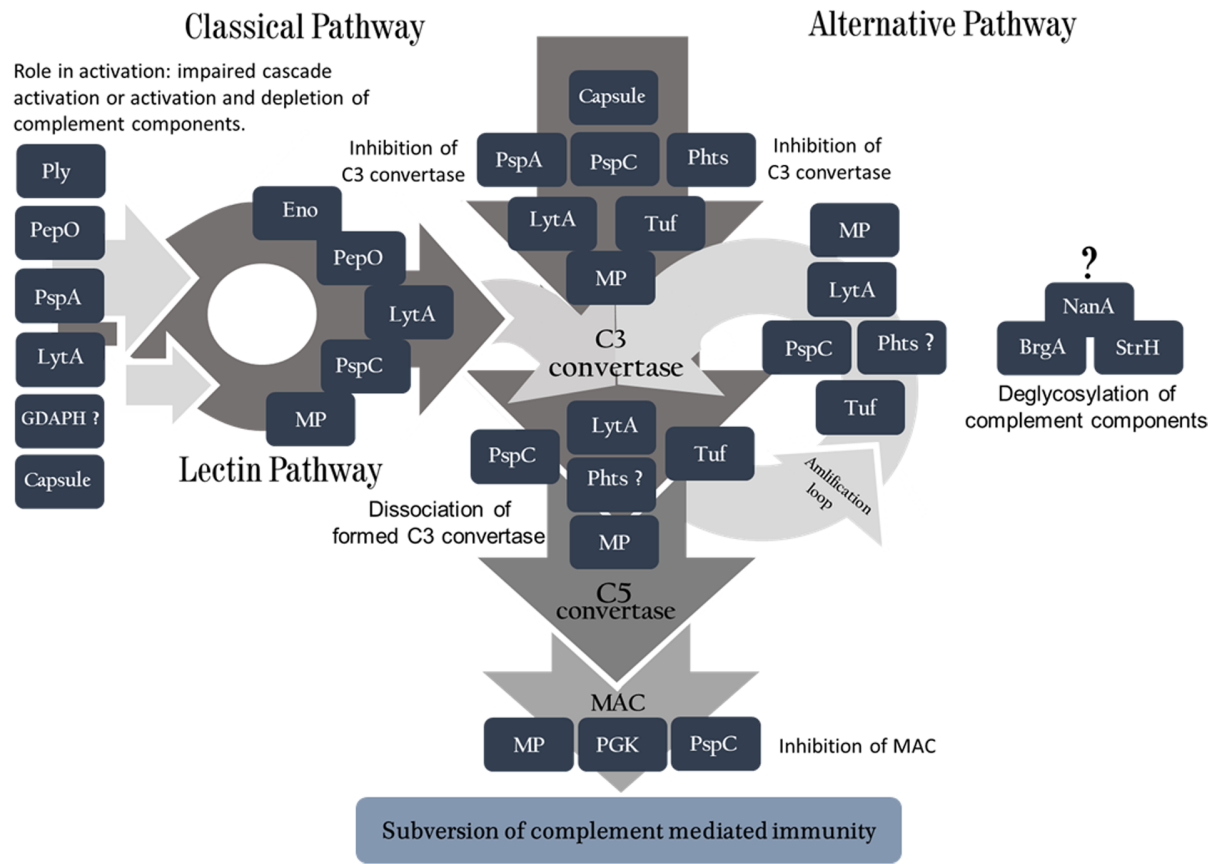

FIGURE 1 | (A) Complement System activation pathways. The classical pathway is activated by binding of C1q molecules to lgM or lgG. C1s cleaves C4 into C4a and C4b, further degrading C2 when bound with C4b, forming C2b (free molecule) and C2a, which remains bound to C4b forming C4bC2a (C3 convertase of the classical pathway). The lectin pathway is activated in a similar fashion, by binding of MBL molecule to mannose or other sugars on microbial surfaces. It can also be initiated by ficolins or collectins. Upon target binding, MASP-1 autoactivates first, and then it activates MASP-2. MASP-2 then cleaves C4 and both enzymes cleave $\mathrm{C} 2$, generating the classical C3 convertase (C4b2a). A third serine protease, MASP-3, is able to activate pro-Factor D (pro-FD) in the resting human blood, favoring alternative complement pathway activation. The Alternative pathway is activated continuously by spontaneous hydrolysis of C3 into C3 $\left(\mathrm{H}_{2} \mathrm{O}\right)$; FB binds to this molecule and is split up by FD, yielding $\mathrm{Ba}$ and $\mathrm{Bb}$ that remains bound to form $\mathrm{C} 3\left(\mathrm{H}_{2} \mathrm{O}\right) \mathrm{Bb}$ (the initial alternative pathway $\mathrm{C} 3$ convertase). This convertase is able to cleave C3 in the blood, generating C3a and C3b, which attaches to the activating surface and recruits FB. Binding of C3b with the cleavage product of FB, Bb,

(Continued) 


\section{FIGURE 1 | (Continued)}

generates the second C3convertase of the alternative pathway, C3bBb. The amplification loop is initiated when plasmatic C3 is cleaved by C3 convertase from all three pathways yielding more C3b, which may lead to more convertase or promote microbial opsonization. The C5 convertase is formed by association of one C3b molecule to the $\mathrm{C} 3$ convertase (in all pathways). This aggregate cleaves $\mathrm{C} 5$ molecules into C5a (anaphylatoxin) and C5b, which is the platform for C6 binding. Following the cascade, C7, C8, and C9 (16-18 units) molecules bind to the activated surface to form the membrane attack complex. (B) Pneumococcal virulence factors act on different points of the complement cascades. Each pneumococcal antigen is depicted in relation to the complement components they interact with. PLY, GDAPH and PepO promote activation and depletion of complement components. PspA inhibits activation of both classical (CP) and alternative pathways (AP) C3 convertases; LytA inhibits classical pathway activation. PspC, PepO, Eno, and LytA undermine CP C3 convertase formation. PspC, Phts, LytA, and Tuf impair AP C3 convertase formation, as well as the amplification loop. PGK and PspC inhibit MAC assembly. NanA, BgaA, and StrH remove sialic acids from complement components, limiting complement mediated phagocytosis; they inhibit AP, but the mechanism responsible for the inhibition is not clear. The pneumococcal moonlighting proteins (MP) have indirect influence on complement through their interaction with PLG and consequent degradation of complement components.

while M-ficolin interacts with $\mathrm{N}$-acetylmannosamine in capsular types 19B and 19C (Kjaer et al., 2013). As a result of this recognition, the complement proteolytic cascade continues as described for the classical pathway [reviewed in (Merle et al., 2015a)].

As observed for the classical pathway, genetic deficiency in MBL is related to an increased susceptibility to pneumococcal disease (Roy et al., 2002). A meta-analysis on human studies suggested that MBL deficiency may be associated with susceptibility to invasive pneumococcal disease (Garcia-Laorden et al., 2013). This was confirmed by Brouwer et al. (2013) in a cohort study, showing that MBL deficiency was associated with a considerable increase in susceptibility to meningitis caused by S. pneumoniae (Brouwer et al., 2013).

The alternative pathway is initiated when $\mathrm{C} 3\left(\mathrm{H}_{2} \mathrm{O}\right)$ - resulting from spontaneous hydrolysis of C3 (Pangburn et al., 1981) is recognized by factor $\mathrm{B}(\mathrm{FB})$ which is then cleaved in factor $\mathrm{Ba}$ and factor $\mathrm{Bb}$ by factor $\mathrm{D}(\mathrm{FD}) ; \mathrm{Bb}$ remains attached to C3 $\left(\mathrm{H}_{2} \mathrm{O}\right)$, forming the soluble phase $\mathrm{C} 3$ convertase of the alternative pathway. This convertase is able to cleave $\mathrm{C} 3$ in the blood, generating C3a and C3b; if C3b is formed close enough to the cell membrane, it will covalently attach to that surface and, because it is structurally similar to $\mathrm{C} 3\left(\mathrm{H}_{2} \mathrm{O}\right)$, it will recruit $\mathrm{FB}$ and the cascade will proceed on the activating surface (Pangburn et al., 1983). The activation cascade triggered by the alternative pathway was found to be related to the density of $\mathrm{C} 3 \mathrm{~b}$ deposited on the bacterial surface (Jarva et al., 2003), which can be translated in more opsonization of pneumococci. Also, the observation that knockout mice for alternative pathway proteins, such as factor B and factor D, are more susceptible pneumococcal infections by strains which lack important virulence factors strongly suggests that this complement pathway contributes to pneumococcal clearance by the host. This will be discussed in more detail further.

Other molecules - including C-reactive protein (CRP) (Biro et al., 2007; Gang et al., 2015), surfactant protein A (S-PA) (Watford et al., 2001; Madhukaran et al., 2015), serum amyloid P (SAP) (Yuste et al., 2007) and molecules of the coagulation cascade (Muhlfelder et al., 1979; Sims et al., 1988; Amara et al., 2010; Rayes et al., 2014; Kim et al., 2015) can activate complement. Particularly CRP and SAP recognize S. pneumoniae and induce complement activation on this bacterium (Yuste et al., 2007; Gang et al., 2015). Both have collagen binding sites which promote binding to $\mathrm{C} 1 \mathrm{q}$ and are able to interact with polysaccharides (PS), lipopolysaccharides
(LPS), and phosphocholine (PCh) on microbial surfaces (Kaplan and Volanakis, 1974; Szalai et al., 1995; Yuste et al., 2007; Gang et al., 2015). CRP was shown to protect mice against pneumococcal infection by binding to Phosphocholine (PCh), but also by mechanisms independent on PCh (Gang et al., 2015). Interestingly, CRP has been implicated in the regulation of complement by binding to regulators, $\mathrm{C} 4 \mathrm{BP}$ and factor $\mathrm{H}$, modulating the classical and alternative pathways, respectively (Biro et al., 2007). A second role of CRP on complement activation has been shown in pneumococci lacking PspC, where the presence of CRP increased binding to FH (Jarva et al., 2002). SAP has also been shown to increase complement deposition on pneumococci by the classical pathway, leading to a more efficient bacterial clearance; mice genetically deficient in SAP were more susceptible to fatal pneumococcal infection, a condition that was partially ameliorated by supplementation with human SAP (Yuste et al., 2007).

The main result of complement activation by $S$. pneumoniae is an increase in bacterial phagocytosis. Alveolar and monocytederived macrophages play a central role in pneumococcal clearance during subclinical pulmonary infections, mainly through production of reactive nitrogen species (MacMicking et al., 1997). Apoptosis has also been demonstrated to aid pneumococcal clearance by macrophages which have exhausted their capacity to kill ingested bacteria, in a nitric oxide $(\mathrm{NO})$ dependent manner [reviewed in (Aberdein et al., 2013)]. This initial response is often enough to eliminate the invading bacteria, with no clinical signs of disease. However, when macrophages exceed their clearance capacity and can no longer control bacterial spread, Th cells and neutrophils are recruited. Production of Th1 and Th17 CD4 ${ }^{+}$cytokines contributes to bacterial clearance, with activation of inflammatory responses. Neutrophils are the main phagocytes controlling pneumococcal loads at this stage; they produce proteases - including elastase and cathepsin G - which mediate effective killing of ingested bacteria [reviewed in (Aberdein et al., 2013)]. Phagocytosis of pneumococci by this cell type is highly dependent on complement activation. However, an exacerbated inflammatory response leads to tissue damage and can be deleterious to the host.

Complement-mediated phagocytosis is also an important mechanism of bacterial clearance during otitis media caused by pneumococci, preventing bacterial spread; neutrophils from the circulation reach the middle ear where they recognize and kill bacteria coated with complement products (Sabharwal et al., 2009). Also, a variation in bacterial resistance to phagocytosis 
in this niche has been associated with capsule production ( $\mathrm{Li}$ et al., 2012). Finally, the role of the complement system on nasopharyngeal colonization by pneumococci is related to the prevention of sepsis following mucosal colonization, and not to the bacterial loads in the nasopharynx (Bogaert et al., 2010).

\section{PNEUMOCOCCAL VIRULENCE FACTORS INTERFERE WITH COMPLEMENT ACTION}

The ability to resist opsonization by C3 is considered crucial not only during systemic infection, but also for persistence of pneumococci in the host nasopharynx (Brown et al., 2002; Kerr et al., 2005; Paterson and Mitchell, 2006; Paterson and Orihuela, 2010) allowing further spread to other host niches. In order to evade complement attack, the pneumococcus has evolved multiple virulence factors that contribute to complement resistance. A thick polysaccharide capsule acts in conjunction with several surface proteins and toxins to limit complement activation and/or accelerate complement products decay. The importance of each of these molecules to complement evasion will be discussed in the following sections. Table $\mathbf{1}$ and Figures 1B and 2 summarize the role of the individual components on complement.

\section{Pneumococcal Polysaccharide Capsule: The Major Virulence Factor}

The vast majority of clinically important isolates of S. pneumoniae are surrounded by a polysaccharide capsule with a highly diverse composition; 97 different capsular types have been identified to date (Geno et al., 2015). The capsule inhibits the activation of both classical and alternative complement pathways, protecting pneumococci against phagocytosis (Hyams et al., 2010a). The bulky polysaccharide structure limits binding of complement molecules, and also prevents the interaction of surface-bound complement fragments with receptors on host cells. Additionally, the capsule inhibits degradation of $\mathrm{C} 3 \mathrm{~b}$ bound to the pneumococcal surface into iC3b (Hyams et al., 2010a), resulting in a decreased $\mathrm{iC} 3 \mathrm{~b} / \mathrm{C} 3 \mathrm{~b}$ ratio, which could impact on complement-mediated bacterial interaction with CR3 on phagocytes. Therefore, protection afforded by the capsule is able to reduce the opsonic capacity of the complement system.

It has been demonstrated that the capsule inhibits binding of IgG, IgM, and CRP to S. pneumoniae (Hyams et al., 2010a). In the same work, Hyams et al. (2010a) used C1qdeficient serum (unable to activate the classical pathway) to show an increase in alternative pathway-mediated $\mathrm{C} 3 \mathrm{~b} / \mathrm{iC} 3 \mathrm{~b}$ deposition on non-encapsulated strains. Similar results were found in other studies, which suggest a role for capsule in the blockage of both classical and alternative complement pathways (Abeyta et al., 2003; Hyams et al., 2010a, 2013). Noteworthy, variations in the ability of different pneumococcal serotypes to interfere with PspC-mediated $\mathrm{FH}$ binding showed a negative correlation with their invasiveness (Hyams et al., 2013). In that work, the levels of FH binding directly impacted on the $\mathrm{C} 3 \mathrm{~b} / \mathrm{iC} 3 \mathrm{~b}$ deposition and neutrophil association, suggesting that pneumococcal capsule types may influence phagocytosis through their effects on FH binding. The polysaccharide capsule also plays a role in preventing the immune adherence of pneumococci - a complement-dependent process in which the bacteria bind to erythrocytes, are transported and transferred to macrophages, which results in reduction of the phagocytic activity against encapsulated pneumococci (Li et al., 2009).

TABLE 1 | Pneumococcal virulence factors: anticomplement activities.

\begin{tabular}{|c|c|c|}
\hline Factors & Target molecule & Effects \\
\hline Capsule & $\operatorname{lgM}, \lg G, \mathrm{CRP}, \mathrm{C} 3$, and iC3b & Prevents complement activation. Inhibits bacterial opsonization by C3b and iC3b. \\
\hline PspA ${ }^{a}$ & CRP and FB & Inhibits CRP deposition and C3 convertase formation \\
\hline PspC & FH, C4BP, Vitronectin, C3 & Inhibits C3 convertase formation and MAC assembly. \\
\hline Ply & C1q, IgG, and L-Ficolin & Activates complement away from bacterial cells and depletes complement components. \\
\hline Phts ${ }^{a *}$ & $\mathrm{FH}$ and $\mathrm{C} 3$ & Inhibits C3 convertase formation. \\
\hline NanA/BgaA/StrH & - & Deglycosylate complement components. \\
\hline LytA ${ }^{b}$ & $\mathrm{FH}, \mathrm{C} 4 \mathrm{BP}, \mathrm{C} 3 \mathrm{~b}$, and iC3b & Inhibits C3 convertase formation and reduces opsonization by iC3b. \\
\hline LytB $^{a}$ & - & Lytic activity promotes bacterial dispersion which limits complement deposition \\
\hline PepOc & C1q, C4BP, PLG & Activates and depletes complement. Inhibits C3 convertase formation. \\
\hline $\mathrm{GAPDH}^{\text {acd }}$ & C1q, PLG & Activates and depletes complement. \\
\hline Eno ${ }^{\mathrm{cd}}$ & C4BP, PLG & Inhibits C3 convertase formation and depletes complement. \\
\hline PGKe & $\mathrm{C} 5, \mathrm{C} 7, \mathrm{C} 9$, and PLG & Inhibits MAC formation and depletes complement. \\
\hline Tuf $_{\text {sp }}{ }^{e}$ & $\mathrm{FH}, \mathrm{FHL}-1, \mathrm{CFHR}-1$, and PLG & Inhibits C3 convertase formation and depletes complement. \\
\hline RrgA & CR3 & Promote adhesion to and invasion of macrophages. \\
\hline
\end{tabular}

a Possible mechanism; not completely elucidated.

$\mathrm{b}$ Indirect activity. Inhibits binding between C1q and CRP.

c Explores PLG in order to improve adhesion and colonization.

dPossibly cleaves/depletes complement components by binding to PLG, but this was not investigated.

e Binding to PLG possibly improves adherence and invasion, but this was not investigated.

*Two studies found conflicting results for Pht binding to $\mathrm{FH}$. 


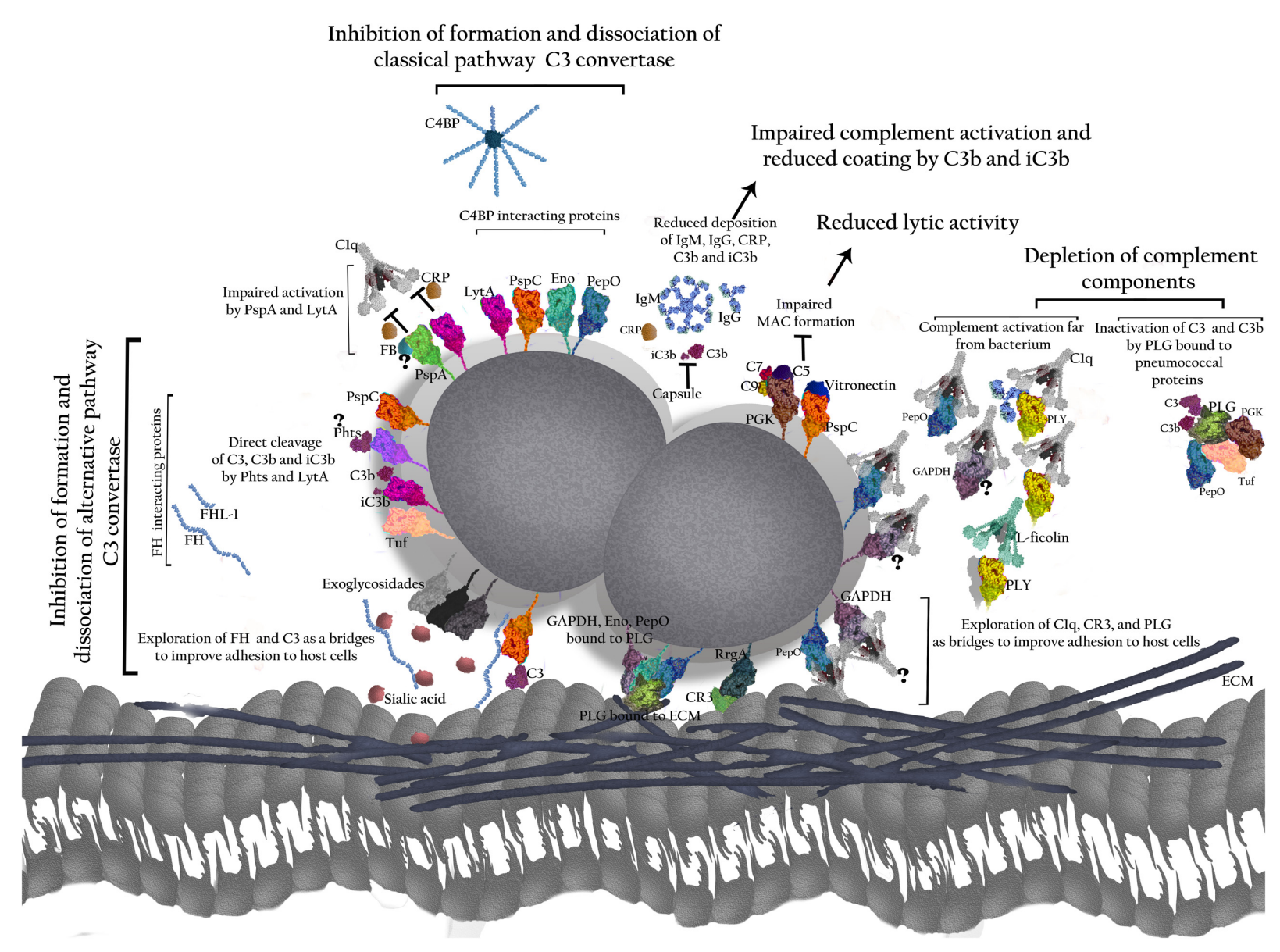

FIGURE 2 | Role of pneumococcal virulence factors in evasion from the Complement System. The polysaccharide capsule prevents binding of IgG, IgM, and CRP to the bacterial surface, as well as $\mathrm{C} 3 \mathrm{~b}$ and iC3b, thereby impairing complement activation by classical (CP) and alternative pathways (AP). The proteins have been grouped according to their interactions with complement. T indicates direct inhibition by pneumococcal antigens. PspA affects C3 convertase formation by interfering with FB and prevents CRP binding to phophocholine on the bacterial wall, thus inhibiting activation of the classical pathway. PspC binds to FH and C4BP promoting the inhibition of C3 convertase formation and accelerating C3 convertase decay. PspC also cleaves C3 molecules generating products that cannot activate complement. Binding of PspC to Vitronectin reduces MAC formation. Phts bind to FH and cleave C3. LytA binding to FH and C4BP reduces C3 convertase formation and promotes its dissociation. It also inhibits the interaction between CRP and C1q. In addition, LytA is able to split up C3b and iC3b. PLY released from the bacterium activates the classical pathway through interactions with IgG, C1q, and L-ficolin, and depletes complement. The exoglycosidases NanA, BgaA, and $\mathrm{StrH}$ remove sialic acid (SA) from complement components; also, SA favors FH activity in regulation of C3 convertase. PepO binds to $\mathrm{C} 1 \mathrm{q}$ and activates complement when released from the pneumococcal surface, leading to depletion of complement components. PepO binding to C4BP results in down regulation of classical pathway activation. Eno decreases C3 convertase formation by binding to C4BP. GAPDH on its free form or attached to the bacterial surface binds to C19, likely promoting complement activation. PGK impairs MAC assembly by binding to C5, C7, and C9. Tuf binds to FH and FHL-1 inhibiting formation and accelerating dissociation of $\mathrm{C} 3$ convertase. Tuf can also bind to CFHR-1, but the implications of this interaction are not completely elucidated. The main result of such interactions is an impaired bacterial phagocytosis. Also, pneumococcal proteins use complement molecules as bridges to interact with host receptors and favor bacterial adherence and invasion. PspC exploits FH to adhere and invade host cells. PepO uses C1q to increase bacterial adherence. RrgA improves colonization by binding to complement receptor 3 (CR3). Finally, the ability to interact with PLG - as demonstrated for PepO, Eno, and GAPDH with PLG was shown to degrade the host extracellular matrix components (ECM) and to improve invasion, while PepO, PGK and Tuf bound to PLG inactivate C3 and C3b.

Interestingly, the extension of complement resistance provided by the capsule varies depending on the bacterial serotype. Mutant strains with a TIGR4 background and capsular types 4 or $7 \mathrm{~F}$ were more resistant to complement deposition and phagocytosis than those expressing polysaccharides $6 \mathrm{~A}$ or $23 \mathrm{~F}$ (Hyams et al., 2010b). Furthermore, this increased resistance to complement deposition correlated with an increased virulence for those strains in a mouse model of pneumococcal sepsis. Accordingly, a study investigating a serotype $11 \mathrm{~A}$ pneumococcal strain found a correlation between the low invasiveness of this isolate and the presence of $\mathrm{O}$-acetylated epitopes in the polysaccharide structure, which were recognized by ficolin- 2 and activated the lectin pathway, leading to bacterial phagocytosis (Brady et al., 2014).

On a whole, the evidence suggests that capsular polysaccharides play a central role in pneumococcal escape from complement system through multiple mechanisms, impacting the bacterial ability to cause disease. 


\section{Pneumococcal Proteins as Sentinels against the Complement System}

Besides the capsule, pneumococci express many proteins that interact with the complement system and promote an increased survival against this important host defense mechanism. These molecules contribute to virulence, as they are essential to the progression of disease and usually found on the bacterial surface, cytosol, in the cell wall or even being released to the environment. Among the anti-complement proteins are PspA, PspC, Phts, LytA, LytB, LytC, NanA, SrtH, BrgA, PLY, PGK, Eno, GAPDH, $\mathrm{PepO}$, and Tuf, which will be discussed individually in the following sections.

\section{Pneumococcal Surface Protein A (PspA)}

Pneumococcal surface protein A is present in virtually all pneumococcal isolates, independently of the serotype. It attaches to phosphocholine residues on the cell wall through the C-terminus, while the N-terminal domain is exposed on the bacterial surface (Yother and Briles, 1992); this region presents a pattern of sequence variation that was used to classify PspA proteins into six clades, included in three families (Hollingshead et al., 2000). All families are involved with inhibition of complement activation ( $\mathrm{Tu}$ et al., 1999; Ren et al., 2003, 2004b) in the early phases of infection (Ren et al., 2004b), although the molecular mechanism of PspA interaction with complement has not been completely elucidated. A recent study demonstrated that PspA competitively inhibits binding of CRP to the phosphocholine moieties on the bacterial wall, thus limiting complement deposition through the classical pathway (Mukerji et al., 2012).

The inhibition of C3 deposition by PspA was attested by the observation that pneumococci lacking PspA were less virulent and more susceptible to $\mathrm{C} 3$ deposition than the wild-type strain, while the virulence of the $\mathrm{PspA}^{-}$strain was recovered in complement factor B-deficient knockout mice ( $\mathrm{Tu}$ et al., 1999). This evidence suggests that the inhibitory role of PspA over complement is related to $\mathrm{FB}$ activation, indicating an important contribution for the alternative complement pathway. In contrast, an in vitro study from (Ren et al., 2004b) found that $\mathrm{C} 3 \mathrm{~b}$ deposition on mutant pneumococci lacking PspA was dependent on the classical pathway activation, since blockage of the classical pathway (with EGTA) - but not the alternative pathway (using sera from FB deficient mice) completely abrogated C3 deposition in the absence of PspA. However, when both complement pathways were present, C3 deposition on the $\mathrm{PspA}^{-}$strain was much greater than with either pathway alone (Ren et al., 2004b). The authors conclude that while the classical pathway is required for activation of complement on $\mathrm{PspA}^{-}$pneumococci, the alternative pathway is responsible for the amplification of $\mathrm{C} 3$ deposition (Ren et al., 2004b).

A study investigating the effects of PspA on complement mediated defense against pneumococci in vivo demonstrated a role for complement receptors CR1/2, since bacteria lacking PspA become virulent in knockout mice for this receptor. Also, mice that did not express factor $\mathrm{D}$ were more susceptible to infection with the $\mathrm{PspA}^{-}$strain, confirming the importance of the alternative pathway for PspA mediated complement inhibition (Ren et al., 2004a). Furthermore, analysis of the fragments derived from $\mathrm{C} 3$ degradation on the pneumococcal surface (C3b and $\mathrm{iC} 3 \mathrm{~b}$ ) showed increased levels of iC3b on the mutant strain, suggesting that PspA prevents processing of $\mathrm{C} 3 \mathrm{~b}$ into $\mathrm{iC} 3 \mathrm{~b}$ (Ren et al., 2004a). Finally, it has been shown that PspA-induced inhibition on complement deposition reduces bacterial clearance by phagocytes in vitro (Ren et al., 2012).

An additional effect of PspA's inhibition of complement deposition is the ability to reduce the immune adherence of the bacterium to erythrocytes (as described for the capsular polysaccharides), thus limiting pneumococcal clearance through phagocytosis (Li et al., 2007). This effect was further enhanced in mutant strains lacking PspA and PspC (another complementinteracting protein that will be discussed in the following section), suggesting that these proteins can act synergistically, promoting a strong complement inhibition (Li et al., 2007).

The anti-complement properties of PspA can be abrogated by host immune response against this protein (Ren et al., 2012). A strong correlation between increased survival and the levels of complement deposited onto pneumococci coated with antiPspA antibodies, has been reported in mice immunized with PspA fragments, suggesting that the blockage of PspA contributes to pneumococcal clearance mediated by complement (Darrieux et al., 2007; Moreno et al., 2010; Goulart et al., 2011). A similar result was obtained using sera from humans immunized with PspA (Ochs et al., 2008). Furthermore, antibodies against PspA purified from mice which had been immunized with heat-killed pneumococci promoted an increase in complement deposition on the bacterial surface (Khan et al., 2015).

Once the bacteria are coated with anti-PspA antibodies and complement, they can be recognized more efficiently by phagocytes and eliminated. Goulart et al. (2011) demonstrated that antibodies induced by mouse immunization with the $\mathrm{N}$-terminal region of PspA from different clades were able to increase phagocytosis of diverse pneumococcal strains by mouse peritoneal phagocytes in presence of a complement source. This effect was confirmed in later studies using different opsonophagocytosis assay (OPA) protocols (Ren et al., 2012; Genschmer et al., 2013) and reinforces the ability of antiPspA antibodies to promote bacterial phagocytosis through complement' activation.

\section{Pneumococcal Surface Protein C (PspC)}

Pneumococcal surface protein $\mathrm{C}$ is a multifunctional protein, able to interact with complement components $\mathrm{C} 3$ (Cheng et al., 2000), human factor H (FH) (Janulczyk et al., 2000; Dave et al., 2001) and the regulator C4BP (Dieudonne-Vatran et al., 2009), and also functions as an adhesion protein, recognizing secretory immunoglobulin A (SIgA) through the secretory component (SC) (Dave et al., 2004; Kerr et al., 2006). PspC also interacts with a laminin-integrin receptor, improving bacterial adherence and spread to other sites (Orihuela et al., 2009). Moreover, PspC displayed affinity to other components of the extracellular matrix, such as thrombospondin-1 and vitronectin, further enhancing bacterial dissemination (Voss et al., 2013; Binsker et al., 2015). 
Pneumococcal surface protein $\mathrm{C}$ contains an N-terminal $\alpha$-helical domain which is exposed at the surface of the bacterium, followed by a proline-rich region and a cell surface-anchoring region (Brooks-Walter et al., 1999). PspCs are classified into 11 groups according to its genetic variation (Iannelli et al., 2002). Different studies demonstrated that PspC from multiple clinical isolates of pneumococci exhibit strong binding to $\mathrm{FH}$ (Lu et al., 2006; Moreno et al., 2012).

Pneumococcal surface protein $\mathrm{C}$ is able to interact directly with $\mathrm{C} 3$ through non-covalent binding to the $\alpha$ and $\beta$ chains of the C3 molecule, preferentially to the alpha fragment (Cheng et al., 2000). Moreover, it has been shown that PspC interacts with $\mathrm{C} 3$ produced by lung epithelial cells, and that this interaction potentiates bacterial adherence (Smith and Hostetter, 2000). The impact of this interaction in pneumococcal disease was confirmed by Kerr et al. (2006) working with infected $C 3^{-/-}$mice; they found that pneumococci lacking PspC presented poor virulence in WT mice, while their potential to cause disease was fully restored in $\mathrm{C} 3$ deficient knockout mice.

Pneumococcal surface protein $\mathrm{C}$ bound to vitronectin inhibited MAC formation (Jarva et al., 2002; Zipfel et al., 2008; Voss et al., 2013; Kohler et al., 2015), thus acting as a complement regulator, while improving the uptake of pneumococci by host cells (Bergmann et al., 2009). Despite the reduced susceptibility of pneumococci to MAC-mediated lysis, the combined effects of $\mathrm{PspC}$ interaction with vitronectin over the complement system contribute to pneumococcal virulence.

Pneumococcal surface protein $\mathrm{C}$ is able to recruit $\mathrm{FH}$ to the pneumococcal surface with a consequent reduction in complement activation, as demonstrated by an in vitro opsonophagocytosis assay (Jarva et al., 2002). PspC-FH interaction has also been shown to occur in vivo (Quin et al., 2005). The interaction between $\mathrm{PspC}$ and $\mathrm{FH}$ inhibits $\mathrm{C} 3 \mathrm{bBb}$ formation by competition with factor $\mathrm{B}(\mathrm{FB})$ (a Bb precursor) for binding to $\mathrm{C} 3 \mathrm{~b}$; it also accelerates irreversible $\mathrm{C} 3 \mathrm{bBb}$ decline by relocating $\mathrm{Bb}$, and acts as a cofactor for factor $\mathrm{I}$ (FI)-catalyzed $\mathrm{C} 3 \mathrm{~b}$ cleavage, yielding iC3b that cannot bind FB (Herbert et al., 2015). More recently, the implications of FH-PspC binding were investigated in vivo, during experimental human colonization with S. pneumoniae (Glennie et al., 2016). The authors found that individuals with epithelial inflammation and increased $\mathrm{FH}$ levels (due to influenza virus infection) had increased bacterial loads after experimental colonization, when compared to healthy subjects. Interestingly, the presence of antibodies against PspC did not affect in vivo binding of $\mathrm{PspC}$ with factor $\mathrm{H}$, possibly because interaction with factor $\mathrm{H}$ limits the recognition of $\mathrm{PspC}$ by specific antibodies (Glennie et al., 2016). Furthermore, FH is exploited by PspC as a bridge to interact with host cells. Simultaneous binding of FH to PspC on the bacterial surface and the CR3 integrin on polymorphonuclear leukocytes (PMN) and CR3 expressing epithelial cells promoted bacterial adhesion and uptake (Agarwal et al., 2010). While the interaction with PMN may favor bacterial clearance, the increased adherence promoted by PspC interaction with $\mathrm{FH}$ is a necessary step for successful colonization (Quin et al., 2007; Agarwal et al., 2010). In fact, the adherence mediated by $\mathrm{FH}$ was related to an increased virulence during lung infection in mice (Quin et al., 2007).
In the biofilm phenotype of pneumococci, the expression of PspC was increased as well as the recruitment of $\mathrm{FH}$. Also, the alternative complement pathway activation was impaired, providing a less propitious condition for phagocytosis (Domenech et al., 2013).

The ability of PspC to avoid complement attack was confirmed by Herbert et al. (2015), who found that FH bound to PspC displays a conformational change which causes an enhanced exposure of C3 binding sites (Herbert et al., 2015). As a result, the interaction of PspC-bound $\mathrm{FH}$ with $\mathrm{C} 3 \mathrm{~b}$ was increased twofold, while the alternative pathway convertase disassociation was increased fivefold (Herbert et al., 2015). In summary, PspC's ability to interact with the complement system is the most important contribution of this molecule to pneumococcal pathogenicity, and provides an interesting target for proteinbased vaccines.

\section{Pneumococcal Histidine Triad (Pht)}

Pneumococcal histidine triad (Phts) is a family of proteins exposed on the surface of $S$. pneumoniae. This group is composed by four members, PhtA, PhtB, PhtD, and PhtE, which are characterized by the presence of histidine triads $(\mathrm{HxxHxH})$ repeated 5 or 6 times in their amino acid sequences (Adamou et al., 2001). Due to the large number of histidine residues in the triads, it has been suggested that Phts may bind to nucleoside or metals. In fact, Phts demonstrate high affinity for divalent cations, with 5 to 6 zinc binding domains (Adamou et al., 2001; Rioux et al., 2011). Zinc is involved in the positive regulation of Phts. Furthermore, variations in zinc concentration on different host niches correlate with the level of Phts expression; Phts are upregulated in the nasopharynx and lungs - where zinc availability is higher - with a reduced expression in blood (Ogunniyi et al., 2009). Despite the variations in Pht levels in different host niches, immunization with Pht fragments is protective in models of bacterial colonization and sepsis (Godfroid et al., 2011).

It has been suggested that Phts interact with complement factor $\mathrm{H}$. However, studies evaluating the binding of Phts to $\mathrm{FH}$ in vitro revealed conflicting results. Ogunniyi et al. (2009), using FH-enzyme-linked immunosorbent assay and western blot, showed that all Phts bind to factor $\mathrm{H}$, although this interaction was much lower when compared to PspC (positive control). More recently, Melin et al. (2010) used FH-ELISA and demonstrated that Pht proteins did not bind to factor $\mathrm{H}$ in most of the serotypes tested; they concluded that the capsule type influences Phts' ability to interact with FH. In the same work, Melin et al. (2010) used western blot analysis to show that $\mathrm{FH}$ was able to bind to cell lysates of $\mathrm{Pht}^{-}$ pneumococcal strains, an effect that was dependent on the presence of PspC. The contribution of $\mathrm{PspC}$ for $\mathrm{FH}$ binding was attested by the abolished binding of this complement regulator, to mutants lacking PspC; in another experiment using flow cytometry, they showed that among five $\mathrm{Pht}^{-}$mutants of different serotypes, only the type 4 strain was able to interact with factor $\mathrm{H}$. They concluded that the relative contribution of Pht proteins to complement inhibition is likely to be affected by the presence of other pneumococcal proteins and, most 
importantly, depends on the genetic background (Melin et al., 2010).

In summary, the putative role of Phts in the binding to FH remains unclear, although their influence in complementmediated phagocytosis was in fact observed. Studies with mutant strains negative for all Phts show an increased susceptibility to bacterial opsonization by C3. It was also suggested that a PhtA fragment could cleave human C3 (Hostetter, 1999). Therefore, further studies are needed in order to elucidate the role of Phts in complement-mediated immunity, which should contribute to the evaluation of their potential as pneumococcal vaccines.

\section{Murein Hydrolases}

Murein hydrolases are enzymes that degrade and remodel the cell wall, and are classified based on the substrate they target. This family of proteins includes amidases, glucosaminidases, muramidases (also termed as lysozymes), endopeptidases and transglycosylases. S. pneumoniae exhibits three main murein hydrolases: LytA, LytB, and LytC.

Lyt $\mathrm{A}, \mathrm{B}$, and $\mathrm{C}$ are choline binding proteins attached to the pneumococcal surface, involved in pneumococcal cell division particularly LytB (Garcia et al., 1999) and cell wall remodeling (Gosink et al., 2000; Bai et al., 2014). They have also been shown to improve the adhesion/colonization of human and rat nasopharyngeal cells (Gosink et al., 2000; Bai et al., 2014). The loss of LytB and LytC expression results in an increased susceptibility to phagocytosis by alveolar macrophages and neutrophils (Ramos-Sevillano et al., 2011).

LytA interacts with the complement system in many ways. It binds to $\mathrm{C} 4 \mathrm{BP}$ and $\mathrm{FH}$, preventing complement deposition by classical and alternative pathways (Ramos-Sevillano et al., 2015). It has also been demonstrated that LytA inhibits binding of C1q to CRP, which was related with an increased exposure of Phosphocholine molecules in the LytA-negative mutant strain (Ramos-Sevillano et al., 2015). LytA can cleave C3b and iC3b fragments deposited in the bacterial surface regardless of the presence of capsule (Ramos-Sevillano et al., 2015), reducing opsonic activity and subsequent phagocytosis. Indeed, phagocytosis by neutrophils and alveolar macrophage cells was described to be higher in the lytA mutant strain (Ramos-Sevillano et al., 2012). The mutant strain also displayed an increased complement deposition when compared with the parental strain expressing autolysin (Ramos-Sevillano et al., 2012).

LytC negative pneumococci show an increased C3b deposition on their surface, an effect that was not observed with the LytB mutant (Ramos-Sevillano et al., 2011). However, despite the absence of a direct effect of LytB alone on complement deposition, a double mutant lacking LytB and LytC revealed a higher sensitivity to $\mathrm{C} 3 \mathrm{~b}$ deposition when compared with the single LytC mutant (Ramos-Sevillano et al., 2011). This suggests a contribution of both proteins to control complement deposition on pneumococci, an effect that was related to increased virulence in models of colonization and invasive disease in presence of LytB and LytC (Ramos-Sevillano et al., 2011).

Despite the evidence of LytA, LytB and LytC involvement in complement resistance by $S$. pneumoniae, the exact mechanism by which they confer resistance to complement is not completely clear. It is possible that the chain-dispersing function of these hydrolases influences the amount of $\mathrm{C} 3$ deposition on the bacterial surface. Growing of S. pneumoniae in biofilms was shown to reduce complement deposition and confer resistance to its opsonic activity and subsequent phagocytosis, when compared to bacteria in diplococci morphology. Indeed, the absence of LytA and LytB was found to promote formation of long chains of pneumococci, while the WT strain yielded diplococci morphology (Domenech et al., 2013). In addition, treatment of long pneumococcal chains with LytB led to bacterial dispersion into diplococci or short chains (De Las Rivas et al., 2002; Dalia and Weiser, 2011; Domenech et al., 2013). This result suggests a link between colony morphology and complement deposition on pneumococci, while indicating a role for autolysins in this mechanism.

\section{Pneumolysin (PLY)}

Pneumolysin (PLY) is a cytotoxic protein produced by all strains of $S$. pneumoniae, found in the cytosol and cell wall compartments (Price and Camilli, 2009), and also being released from the bacterium during cell growth (Balachandran et al., 2001). PLY displays many important functions during pneumococcal infections, including (i) hemolytic and genotoxic effects (Johnson et al., 1980; Rai et al., 2016); (ii) induction of apoptosis in different cells - including macrophages and brain cells (Braun et al., 2001; Srivastava et al., 2005); (iii) interaction with TLR-4 and production of inflamatory cytokynes (Malley et al., 2003); (iv) activation of NLRP3 inflamasome (McNeela et al., 2010); (v) induction of neutrophil extracelullar trap (NET) formation (Nel et al., 2016); (vi) inhibition of cilliary movements in epithelial respiratory cells (Rayner et al., 1995; Marriott et al., 2008) and (vii) complement activation (Paton et al., 1984; Mitchell et al., 1991; Benton et al., 1997; Alcantara et al., 2001; Jounblat et al., 2003; Yuste et al., 2005; Propst-Graham et al., 2007; Marriott et al., 2008; Ali et al., 2013).

Pneumolysin's ability to activate complement - which could be interpreted as disadvantageous for pneumococci - has actually been reported as a protective mechanism for the pathogen; since PLY is only exposed to interact with complement when it is released from the bacterium (the cell wall-attached molecule is not accessible to recognition by antibodies or complement), it has been suggested that complement activation by PLY causes depletion of complement components in the serum (Paton et al., 1984; Mitchell et al., 1991), thus limiting complement binding to the pneumococcus. This effect was confirmed in vivo using mutant strains that produce truncated forms of the toxin (Rubins et al., 1995; Alcantara et al., 2001; Propst-Graham et al., 2007); in a lung infection model, a mutant strain expressing a PLY which lacks the complement activation activity displayed a marked reduction in bacterial loads in the mice lungs (Rubins et al., 1995; Propst-Graham et al., 2007). Similarly, complementation of a PLY negative mutant with a recombinant PLY presenting intact complement activation capacity but no hemolytic activity was able to restore the bacterial virulence, indicating an independent contribution of the complement activation motif of PLY for pneumococcal virulence in this infection model (Rubins et al., 1995). However, in models of pneumococcal bacteremia, a 
significant role for the complement activity of PLY was only observed in cirrhotic rats (which produce reduced amounts of complement), with no effect in animals exhibiting normal complement production (Alcantara et al., 1999). This result suggests that the contribution of the complement activation motif of PLY is important in host niches or systems where a limited amount of complement is available (Propst-Graham et al., 2007; Marriott et al., 2008).

Pneumolysin's ability to activate complement occurs mainly through the classical pathway; in fact, a direct interaction of PLY with $\mathrm{C} 1$ has been described in vitro (Paton et al., 1984) and related to a specific region of PLY that shows homology to human CRP, located in the domain 4 (Mitchell et al., 1991). PLY also shows structural similarity with the Fc portion of immunoglobulin, being able to bind Ig (Mitchell et al., 1991). Interestingly, the region involved in interaction with Ig is the same responsible for PLY self-oligomerization, suggesting one mechanism by which PLY promotes the complement activation [reviwed in (Marriott et al., 2008)]. However, complement activation by PLY is not dependent on the presence of specific anti-PLY antibodies, since sera from unvaccinated humans and non-immune mice showed increased C3 deposition on pneumococci lacking PLY (Yuste et al., 2005). Additionally, the contribution of PLY to complement-mediated inflammatory response may be enhanced by the fragments generated from complement activation (C3a and C5a), which attract polymorphonuclear cells, as already seen in serum containing high amounts of PLY (Johnson et al., 1981).

The observation that human serum (but not mice) depleted from C1q still promotes PLY opsonization by C3 activation products suggests a role for the lectin pathway in PLY-induced complement activation (Ali et al., 2013). In fact, human L-ficolin has been shown to initiate MBL activation by PLY in human serum, contributing to the classical pathway activation (Ali et al., 2013).

In addition to its direct role in complement activation, PLY participates in the assembly of pneumococcal biofilms (Shak et al., 2013) - a phenotype that is important for successful colonization and during the early stages of invasive infections, as well as limiting the interaction of complement components with surface molecules of pneumococci (Hall-Stoodley et al., 2006; Domenech et al., 2013). Therefore, the involvement of PLY on biofilm formation indirectly contributes to evasion from complement.

In summary, the contribution of PLY to pneumococcal virulence - which is highly influenced by the ability to interact with the complement system - reinforces the importance of complement evasion for bacterial survival, as well as PLY's potential as a vaccine candidate against this pathogen.

\section{Pneumococcal Exoglycosidases}

The pneumococcal exoglycosidases are a group of enzymes that cleave terminal sialic acid from glycoconjugates. Among five exoglycosidases expressed by pneumococci - NanA, NanB, NanC, BgaA, and StrH, three surface associated molecules have been shown to interact with complement: NanA, BgaA, and StrH.

Neuraminidase A (NanA) is able to remove the sialic acid (SA) from a range of host substrates, thereby promoting the interaction between pneumococci and host cell receptors that contribute to pneumococcal colonization (Tong et al., 2000; Brittan et al., 2012). BgaA is the only pneumococcal $\beta$-galactosidase; it is secreted and acquired by the pneumococcal surface through a sortase. BgaA exhibits affinity to terminal galactose $\beta$ (1-4) linked to GlcNAc, suggesting a role in deglycosylation of glycoconjugates of human cells (?) and was shown to be an adhesin, regardless of its galactosidase activity (Limoli et al., 2011). $\mathrm{N}$-acetylglucosaminidase (StrH) is an exoglycosidase found in the bacterial surface and supernatant, able to cleave $\mathrm{N}$-acetylglucosamine (GlcNAc) that is linked to mannose through $\beta-1$ (Zähner and Hakenbeck, 2000). All three proteins have been reported to work sequentially in the deglycosylation of $\mathrm{SA}$, galactose, $\mathrm{N}$-acetylglucosamine, decrypting mannose of host glycoproteins, which favors adherence/colonization (King et al., 2006).

These proteins have also been shown to deglycosylate human glycoconjugates as lactoferrin and IgA (King et al., 2006), demonstrating a direct interaction with the immune system. Indeed, SA participates in several immune processes such as leukocyte rolling, cell activation, modulation of immune cell functions and interactions with the complement system [reviewed in (Varki and Gagneux, 2012)].

NanA, BgaA, and StrH were shown to act in conjunction to limit complement deposition on pneumococci of different genetic backgrounds (Dalia et al., 2010). Blocking of the classical pathway did not affect complement levels on the bacterial surface, suggesting that NanA acts on the alternative pathway (Dalia et al., 2010). These proteins were also shown to inhibit bacterial killing by human phagocytes in vitro. This effect was attributed to the sequential removal of sugar moieties from host glycoconjugates by NanA, BgaA, and StrH: NanA removes sialic acid that is $\alpha 2-3$ or $\alpha 2-6$ linked to galactose, BgaA excises the galactose that is $\beta 1-4$ linked to $\mathrm{N}$-acetylglucosamine, and $\mathrm{StrH}$ removes $\mathrm{N}$-acetylglucosamine that is $\beta 1$ linked to mannose (King et al., 2006). Since complement components contain many glycosylation sites which are necessary for their functions [reviewed in (Ritchie et al., 2002)], the sequential activities of NanA, BgaA, and StrH possibly deglycosylate one or more glycoproteins that are important for complement deposition, thus leading to inhibition of complement mediated opsonophagocytosis (Dalia et al., 2010).

Previous studies found a role for SA in subversion of complement alternative pathway. SA is required for effective binding between $\mathrm{FH}$ and surface-attached $\mathrm{C} 3 \mathrm{~b}$, as well as for dissociation of C3 convertase in sheep erythrocytes (Fearon, 1978). Pathogens like Neisseria meningitidis and Haemophilus influenzae exploit this complement-evasion strategy by producing SA that binds factor H (Ram et al., 1998). Interestingly, NanA from S. pneumoniae is able to remove sialic acid from the surface of these pathogens, thus limiting their ability to escape complement attack, providing a competitive advantage for pneumococci (Shakhnovich et al., 2002).

In summary, despite the evidence of exoglycosidases role in complement evasion, further investigations are required in 
order to elucidate the exact mechanism by which these proteins circumvent complement activation.

\section{Pneumococcal Pilus Adhesine (RrgA)}

Streptococcus pneumoniae expresses a pilus-like structure, encoded by the rlrA pilus islet 1, which contributes to virulence in animal models of pneumococcal infection (Barocchi et al., 2006). This structure is composed of three proteins: RrgA, RrgB, and RrgC (Barocchi et al., 2006; Hilleringmann et al., 2009). RrgA is an adhesin that interacts with lung epithelial cells in vitro and confers virulence in mice (Barocchi et al., 2006; Hilleringmann et al., 2009). It is also able to increase bacterial phagocytosis by murine and human cells (Hilleringmann et al., 2009). Orrskog et al. (2012), using flow cytometry have shown that purified complement receptor 3 (CR3) binds to pneumococci expressing RrgA, and that purified RrgA is able to interact with the CD11b integrin domain of CR3. In addition, RrgA expression was linked to a faster dissemination of pneumococci from the upper respiratory tract and peritoneal cavity to the bloodstream of challenged mice, and to an increased bacterial survival inside macrophages (Orrskog et al., 2012). Altogether, the evidence indicate that RrgA interaction with CR3 on the surface of macrophages promotes bacterial internalization, while a prolonged survival of the internalized pneumococci contributes to their dissemination during systemic infection.

\section{Pneumococcal Moonlighting Proteins}

Moonlighting proteins are a group of molecules able to perform distinct biological activities through a single domain. Found in both prokaryotic and eukaryotic cells, these proteins display several activities, including roles in metabolic processes, host-pathogen signaling, transcription activation, adhesion and invasion of host tissues (Henderson and Martin, 2014). Based on their potential to interact with host cells, bacterial moonlighting proteins are important virulence factors in prokaryotic organisms (Jeffery, 1999; Henderson and Martin, 2011).

One important feature shared by many moonlighting proteins is their ability to interact with plasminogen (PLG) (Henderson and Martin, 2011), a plasmatic glycoprotein that generates plasmin (PL) upon activation. PL is a serine protease which displays many functions in tissue remodeling and coagulation. The conversion of PLG into PL is accomplished by activators like urokinase type A (uPA) and tissue type plasminogen (tPA) activators (human molecules) or by bacterial proteins [reviewed in (Lahteenmaki et al., 2001)].

Plasminogen and PL interfere with many molecules of the complement system (Barthel et al., 2012; Castiblanco-Valencia et al., 2016). PL cleaves C1, C2, C3, C3b, C4, and C5 (Pillemer et al., 1953; Amara et al., 2010; Barthel et al., 2012), thereby depleting and inhibiting complement activation through all three complement pathways. Even the enzymatically inactive PLG was able to improve the cofactor activity of $\mathrm{FH}$ in the inactivation of C3b by Factor I (Foley et al., 2015). It also cleaves iC3b, yielding C3dg-like, which acts as an opsonin and an activator of proinflammatory cytokines in macrophages (Foley et al., 2015).
PLG has been found to interact with C3, C5, C3b, C3c, and C3d (Barthel et al., 2012).

Streptococcus pneumoniae expresses moonlighting proteins (Henderson and Martin, 2013), including PepO, enolase, GAPDH, PGK, and Tuf, which are able to acquire surrounding PLG molecules of the host. This interaction has been shown to contribute to invasion of host tissues and to avoid complement attack. The actions of pneumococcal moonlighting proteins are described in more detail below.

\section{Endopeptidase O (PepO)}

Endopeptidase O (PepO) displays a HEXXH motif, an important active site of neutral endopeptidase (NEP) and typical of zinc-dependent metallopeptidases (Rawlings and Barrett, 1995). NEP is a member of M13 peptidase family, involved in many physiological functions and immune responses. Found on the pneumococcal surface and in culture supernatants, endopeptidase $\mathrm{O}$ has been reported to bind plasminogen and fibronectin (constituent of human extracellular matrix) (Agarwal et al., 2013b), thereby coating the pneumococcal surface with these molecules, which facilitate pneumococcal adhesion and invasion of host cells, while inhibiting complement-mediated immunity. Indeed, the binding of PepO to PLG in the presence of uPA was able to cleave C3b (Agarwal et al., 2013b). In addition, PepO has been found to bind to both $\mathrm{C} 1 \mathrm{q}$ (C-terminal globular heads) and C4BP (CCP8 of the $\alpha$-chain) through ionic interactions (Agarwal et al., 2014), with direct implications on complement activation. The ability to bind C1q upon release of PepO promotes complement activation and rapid consumption of complement components around the bacterium, with a consequent inhibition of complement activation on the pneumococcal surface (Agarwal et al., 2014). Further inhibition of complement activation is achieved by interaction with the complement regulator C4BP (Agarwal et al., 2014). Also, the interaction of surface exposed PepO with $\mathrm{C} 1 \mathrm{q}$ increases pneumococcal adherence to host epithelial cells in vitro (Agarwal et al., 2013a, 2014; Agarwal and Blom, 2015).

\section{$\alpha$-Enolase (Eno)}

Pneumococcal $\alpha$-Enolase (Eno) is present in virtually all strains, found in the bacterial cytoplasm, displayed on the surface and released to the culture supernatant. The mechanism of Eno exportation is not completely elucidated, although it does not seem to be dependent on autolysis (Bergmann et al., 2003). It is a glycolytic enzyme involved in conversion of 2-phosphoD-glycerate to phosphoenolpyruvate during glycolysis (Whiting et al., 2002). Similar to other moonlighting proteins, it has been shown to play a role in bacterial adherence to host tissues and invasion by binding to PLG and, consequently, promoting degradation of extracellular matrix components (Bergmann et al., 2005; Bergmann et al., 2013). Eno-deficient pneumococcal mutants displayed reduced binding to PLG, which correlated with a reduced adherence to host cells in vitro (Bergmann et al., 2013).

Pneumococcal Eno exhibits additional roles in virulence. It was reported to ionically bind to C4BP (Agarwal et al., 
2012), consequently coating the surface of pneumococci with this complement regulatory molecule. The binding sites were identified in the CCP domains of $\alpha$-chain in C4BP. It was also reported that Eno can concomitantly bind to C4BP and PLG in a non-competitive fashion, increasing the activation of PLG into plasmin (Agarwal et al., 2015). Furthermore, C4BP bound to Eno on the pneumococcal surface acted as a cofactor in C4d degradation by FI, while leading to a reduction in $\mathrm{C} 3 \mathrm{~b}$ deposition on the bacterium (Agarwal et al., 2012). Additionally, Eno has been shown to interact with neutrophils promoting formation of neutrophil extracellular traps (NETs) which increased their bactericidal effect (Mori et al., 2012). One possible explanation for this apparently disadvantageous interaction is that NETinduced host tissue damage may favor the spread of the microorganism; however, this effect has not been investigated to date.

\section{Glyceraldehyde-3-phosphate Dehydrogenase (GAPDH)}

Glyceraldehyde-3-phosphate Dehydrogenase is a glycolytic enzyme shared by prokaryotic and eukaryotic cells which has been implicated in the pathogenesis of bacterial infections (Jin et al., 2011), acting as an adhesion (Pancholi and Fischetti, 1992; Zhang et al., 2015), a transferrin binding molecule (in both bacteria and human cells) (Modun and Williams, 1999; Raje et al., 2007; Kumar et al., 2012) as well as in host immune modulation and apoptosis (Terao et al., 2006; Terrasse et al., 2012).

Although first identified as a cytoplasmic protein, it has been demonstrated that pneumococcal GAPDH is surface-associated and surface-exposed (Terrasse et al., 2012, 2015), where it can act as an adhesin and bind PLG (Attali et al., 2008). Binding of PLG to pneumococci increased bacterial adherence and invasion of host cells (Attali et al., 2008). GAPDH released through autolysis is also able to bind C1q (Terrasse et al., 2012) and to activate complement. Pneumococci lacking the glycolytic enzyme exhibited reduced binding to PLG and deposition of C1q, C3 and C4 components (Terrasse et al., 2012), evidencing a role of GAPDH in the activation and subsequent deposition of complement.

Glyceraldehyde-3-phosphate Dehydrogenase was reported to bind directly to peptidoglycan regardless of the presence of teichoic or lipoteichoic acids, though a mechanism dependent on LytA-mediated lysis (Terrasse et al., 2015). In the same study, peptidoglycan bound GAPDH showed an increased C1q deposition (Terrasse et al., 2015); however, C1q binding in the presence of GAPDH was not able to activate the complement cascade, suggesting that other molecules may be involved in complement activation in this model (Terrasse et al., 2015).

The implications of binding of GAPDH (free form) to C1q may be similar to those found for PepO, leading to depletion of complement components away from the bacterium, and consequently avoiding complement mediated pneumococcal clearance. However, the precise mechanism of GAPDH - attached to the pneumococcal surface or not - interaction with the complement system has not been investigated.

\section{Phosphoglycerate Kinase (PGK)}

Phosphoglycerate Kinase is a glycolytic enzyme involved in the conversion of 1,3-biphosphoglycerate to 3-phosphoglycerate (Bernstein et al., 1998). As reported for other moonlighting proteins, PGK can be found in supernatants, although the precise mechanism of secretion and surface exposure of this molecule remains unclear. Another similarity with the moonlighting proteins is the ability to bind PLG. Interestingly, in addition to PLG, PGK interacts simultaneously with tissue plasminogen activator - tPA (Fulde et al., 2014), which is responsible for PLG conversion into plasmin, leading to degradation of extracellular matrix proteins and contributing to bacterial invasion and dissemination, while hindering the opsonic effect of the complement system (Fulde et al., 2014).

Furthermore, PKG has recently been reported to bind ionically and simultaneously to MAC proteins (Blom et al., 2014). Pneumococcal MAC-mediated killing, as occurs with other Gram-positive microbes, is found to be ineffective, due to an increased resistance to insertion of $\mathrm{C} 5 \mathrm{~b} 9$ in the membrane protected by a thick peptidoglycan (Blom et al., 2014). The components of the terminal pathway $\mathrm{C} 5, \mathrm{C} 7$, and $\mathrm{C} 9$ were found to interact with $\mathrm{PKG}$, undermining MAC assembly as a result of complement components depletion. Indeed, PGK associated with the pneumococcal surface promoted an inhibition of MAC deposition. These interactions were also able to reduce the hemolytic capacity of human serum against the bacterium. Moreover, PLG bound to PGK was activated in PL, which cleaved C3b (Blom et al., 2014). The impaired assembly of MAC takes place during the initial (by binding C5 and C7) and late phases (by binding C9) of the terminal pathway. The binding domains of C5 and C7 appear to be partially superimposed, while the C9 site in PGK is not; this latter interaction is capable of inhibiting the C9 self-polymerization (Blom et al., 2014).

In summary, the many sites of interaction between PGK and complement proteins suggest a role in pneumococcal ability to avoid complement attack, since complement proteins interacting with PGK ultimately become unavailable to participate in the cascade.

\section{Elongating factor $\mathrm{Tu}\left(\mathrm{Tu} \mathrm{f}_{\mathrm{sp}}\right)$}

The elongating factor $\mathrm{Tuf}_{\mathrm{sp}}$ is a surface-accessible protein from S. pneumoniae, also found in the bacterial cytoplasm and culture supernatants. It is a conserved protein found in different species of bacteria and fungi, including pathogenic and non-pathogenic organisms (Jacobson and Rosenbusch, 1976; Crowe et al., 2003; Archambaud et al., 2005; Gross and Kinzy, 2005; Jonak, 2007; Li et al., 2013; Mohan et al., 2014). Tuf exhibits molecular chaperone activity, being involved in peptide biosynthesis, protein folding and cell response to stress, promoting protein renaturation (Gregersen and Bross, 2010). It is also involved in the transport of amino-acyltRNA to ribosomes (Murase et al., 2003; Nilsson and Nissen, 2005).

Pneumococcal Tuf was described by Mohan and co-workers as a factor $\mathrm{H}$-binding protein, identified through mass spectrometry 
of a gel band from a mutant pneumococcus lacking PspC, which still reacted with Factor $\mathrm{H}$ by western blot (Mohan et al., 2014). The domains of FH responsible for the interaction were CCP 6-7 and 18-20 (heparin site). Tuf was also able to bind to other complement regulators, FHL-1 (a short form of $\mathrm{FH}$ ) and to Factor $\mathrm{H}$ related protein 1 (CFHR-1) (CCP 3-5). The complement regulatory activity promoted by $\mathrm{FH}$ and FHL-1 as cofactors of FI was maintained when they were bound to Tuf. Moreover, the concomitant binding of Tuf and $\mathrm{FH}$ to plasminogen promotes plasmin formation in presence of uPA, which in turn cleaves fibrinogen, C3 and C3b (Mohan et al., 2014). The combined effects of complement inhibition and degradation of ECM components promoted by interaction of Tuf with its many ligands enhance the bacterium's ability to invade host tissues.

\section{COMPLEMENT-INTERACTING PNEUMOCOCCAL PROTEINS AS VACCINES CANDIDATES}

The efficacy of the polysaccharide-based vaccines is attributed to their ability to induce serotype-specific antibodies that promote bacterial phagocytosis, a mechanism that is largely dependent on complement activation (Song et al., 2013). This result reinforces the importance of the complement system to vaccine-induced protection against pneumococcal infection.

Several pneumococcal proteins have been investigated as potential candidates for inclusion in a future pneumococcal vaccine, with encouraging results (Hamel et al., 2004; Gor et al., 2005; Gianfaldoni et al., 2007; Ferreira et al., 2009; Godfroid et al., 2011; Hernani Mde et al., 2011; Kamtchoua et al., 2013; Darrieux et al., 2015). PspA, PspC, Phts, NanA, PLY, RrgA, LytA, and GAPDH have all been demonstrated to induce protection against systemic infection [reviewed in (Darrieux et al., 2015) and (Miyaji et al., 2013)]; PspC, Phts, NanA, and PspA were also protective against nasopharyngeal colonization (Arulanandam et al., 2001; Balachandran et al., 2002; Tong et al., 2005; Hernani Mde et al., 2011), while NanA protects chinchillas against otitis media (Long et al., 2004).

Moreover, the role of complement activation as a protective mechanism promoted by vaccination has been exploited in many studies, including animal models of colonization and invasive disease (Darrieux et al., 2007, 2015; Ogunniyi et al., 2007; Ferreira et al., 2010; Moreno et al., 2010; Paton, 2011; Miyaji et al., 2013). The surface association or microbial release of these proteins further supports their potential as vaccine candidates, allowing immune recognition in vaccinated individuals upon contact with the pathogen. Finally, PspA, PspC, Phts, and Pds (derived from genetically or chemically detoxified PLY) have also been evaluated in clinical trials, and shown to be immunogenic and safe [reviewed in (Darrieux et al., 2015)].

In order to improve vaccine immunogenicity and coverage, combinations of these antigens have been used, with promising outcomes. PspA and PspC have been shown to confer broad protection against colonization and invasive diseases (Ferreira et al., 2009). The inclusion of Phts also promotes potent and protective immune responses. PspA and Pds were able to augment protection against lethal pneumococcal sepsis (Briles et al., 2000). Furthermore, the genetic fusion of pneumococcal antigens has been employed as an alternative strategy to broaden vaccine coverage, while reducing steps in the production process. This is particularly important when considering structurally variable antigens - such as PspA (which is the most promising vaccine candidate so far, but exhibits serological diversity which limits vaccine coverage). In the case of PspA, genetic fusion of molecules from different families (Darrieux et al., 2007), or fusion with Pds (Goulart et al., 2013), showed an enhancement in vaccine coverage.

\section{CONCLUSION}

The high numbers of pneumococcal proteins which are capable of interacting with the complement system highlight the importance of this defense mechanism to limit the diseases caused by this pathogen. Many of these proteins act on the same step of the complement cascade; this redundancy suggests that the loss of one antigen may be compensated by another protein with similar functions.

Several pneumococcal proteins have been evaluated as potential vaccine candidates, with variable outcomes. The emerging concept regarding protein-based pneumococcal vaccines (which has been expanded to other pathogenic bacteria and protozoa) is that the use of one protein alone may not be sufficient to provide long term, wide protection against pneumococcal diseases [reviewed in (Darrieux et al., 2015)]. Therefore, the inclusion of different antigens in a multi-component vaccine formulation has been emphasized as a promising approach to prevent pneumococcal diseases. In this sense, the combination of antigens that act over the same mechanism may be an effective strategy to block immune evasion by the pathogen, allowing for rapid bacterial clearance. Therefore, we suggest that the combination of pneumococcal proteins that act by limiting complement activation on $S$. pneumoniae could provide strong protection against infections caused by this pathogen. In particular, different combinations of PspA, PspC, Phts e PLY (up to three proteins in one formulation) have already been successfully evaluated in animal models and clinical trials. However, the inclusion of high numbers of antigens in a single formulation raises concerns regarding protein interference, and also imposes production limitations. An alternative would be the use of protein chimeras - including immunogenic fragments of the virulence factors genetically fused - which have been shown to preserve individual antigenic properties and even expose previously cryptic epitopes, while increasing vaccine coverage. This would allow the inclusion of new vaccine candidates such as the moonlighting proteins - which can further enhance vaccine efficacy. Nevertheless, more studies are needed in order to determine the protective potential of this vaccine approach. 


\section{AUTHOR CONTRIBUTIONS}

GA, TC, WP, and MD drafted the manuscript. LF, MR, LL, and $\mathrm{MD}$ reviewed the text. All authors read and approved the final manuscript.

\section{FUNDING}

The present work was supported by FAPESP (grant number 2014/01115-9) and CAPES.

\section{REFERENCES}

Aberdein, J. D., Cole, J., Bewley, M. A., Marriott, H. M., and Dockrell, D. H. (2013). Alveolar macrophages in pulmonary host defence the unrecognized role of apoptosis as a mechanism of intracellular bacterial killing. Clin. Exp. Immunol. 174, 193-202. doi: 10.1111/cei.12170

Abeyta, M., Hardy, G. G., and Yother, J. (2003). Genetic alteration of capsule type but not PspA type affects accessibility of surface-bound complement and surface antigens of Streptococcus pneumoniae. Infect. Immun. 71, 218-225. doi: 10.1128/IAI.71.1.218-225.2003

Adamou, J. E., Heinrichs, J. H., Erwin, A. L., Walsh, W., Gayle, T., Dormitzer, M., et al. (2001). Identification and characterization of a novel family of pneumococcal proteins that are protective against sepsis. Infect. Immun. 69, 949-958. doi: 10.1128/IAI.69.2.949-958.2001

Agarwal, V., Ahl, J., Riesbeck, K., and Blom, A. M. (2013a). An alternative role of C1q in bacterial infections: facilitating Streptococcus pneumoniae adherence and invasion of host cells. J. Immunol. 191, 4235-4245. doi: 10.4049/jimmunol. 1300279

Agarwal, V., Asmat, T. M., Luo, S., Jensch, I., Zipfel, P. F., and Hammerschmidt, S. (2010). Complement regulator factor $\mathrm{H}$ mediates a two-step uptake of Streptococcus pneumoniae by human cells. J. Biol. Chem. 285, 23486-23495. doi: 10.1074/jbc.M110.142703

Agarwal, V., and Blom, A. M. (2015). Roles of complement C1q in Pneumococcus-host interactions. Crit. Rev. Immunol. 35, 173-184. doi: 10.1615/ CritRevImmunol.2015012177

Agarwal, V., Hammerschmidt, S., Malm, S., Bergmann, S., Riesbeck, K., and Blom, A. M. (2012). Enolase of Streptococcus pneumoniae binds human complement inhibitor C4b-binding protein and contributes to complement evasion. J. Immunol. 189, 3575-3584. doi: 10.4049/jimmunol.110 2934

Agarwal, V., Kuchipudi, A., Fulde, M., Riesbeck, K., Bergmann, S., and Blom, A. M. (2013b). Streptococcus pneumoniae endopeptidase O (PepO) is a multifunctional plasminogen- and fibronectin-binding protein, facilitating evasion of innate immunity and invasion of host cells. J. Biol. Chem. 288, 6849-6863. doi: 10.1074/jbc.M112.405530

Agarwal, V., Sroka, M., Fulde, M., Bergmann, S., Riesbeck, K., and Blom, A. M. (2014). Binding of Streptococcus pneumoniae endopeptidase O (PepO) to complement component $\mathrm{Clq}$ modulates the complement attack and promotes host cell adherence. J. Biol. Chem. 289, 15833-15844. doi: 10.1074/jbc.M113. 530212

Agarwal, V., Talens, S., Grandits, A. M., and Blom, A. M. (2015). A novel interaction between complement inhibitor C4b-binding protein and plasminogen that enhances plasminogen activation. J. Biol. Chem. 290, 18333-18342. doi: 10.1074/jbc.M114.619494

Alcantara, R. B., Preheim, L. C., and Gentry, M. J. (1999). Role of Pneumolysin's complement-activating activity during pneumococcal bacteremia in cirrhotic rats. Infect. Immun. 67, 2862-2866.

Alcantara, R. B., Preheim, L. C., and Gentry-Nielsen, M. J. (2001). Pneumolysininduced complement depletion during experimental pneumococcal bacteremia. Infect. Immun. 69, 3569-3575. doi: 10.1128/IAI.69.6.3569-3575.2001

Ali, Y. M., Kenawy, H. I., Muhammad, A., Sim, R. B., Andrew, P. W., and Schwaeble, W. J. (2013). Human L-ficolin, a recognition molecule of the lectin activation pathway of complement, activates complement by binding

\section{ACKNOWLEDGMENT}

We gratefully acknowledge the assistance of Stella M. Nadais and José V. da Silva Neto with the illustrations.

\section{SUPPLEMENTARY MATERIAL}

The Supplementary Material for this article can be found online at: http://journal.frontiersin.org/article/10.3389/fmicb. 2017.00224/full\#supplementary-material

to pneumolysin, the major toxin of Streptococcus pneumoniae. PLoS ONE 8:e82583. doi: 10.1371/journal.pone.0082583

Ali, Y. M., Lynch, N. J., Haleem, K. S., Fujita, T., Endo, Y., Hansen, S., et al. (2012). The lectin pathway of complement activation is a critical component of the innate immune response to pneumococcal infection. PLoS Pathog. 8:e1002793. doi: 10.1371/journal.ppat.1002793

Almeda, S., Rosenberg, R. D., and Bing, D. H. (1983). The binding properties of human complement component C1q. Interaction with mucopolysaccharides. J. Biol. Chem. 258, 785-791.

Amara, U., Flierl, M. A., Rittirsch, D., Klos, A., Chen, H., Acker, B., et al. (2010). Molecular intercommunication between the complement and coagulation systems. J. Immunol. 185, 5628-5636. doi: 10.4049/jimmunol.0903678

Archambaud, C., Gouin, E., Pizarro-Cerda, J., Cossart, P., and Dussurget, O. (2005). Translation elongation factor EF-Tu is a target for Stp, a serinethreonine phosphatase involved in virulence of Listeria monocytogenes. Mol. Microbiol. 56, 383-396. doi: 10.1111/j.1365-2958.2005.04551.x

Arulanandam, B. P., Lynch, J. M., Briles, D. E., Hollingshead, S., and Metzger, D. W. (2001). Intranasal vaccination with pneumococcal surface protein A and interleukin-12 augments antibody-mediated opsonization and protective immunity against Streptococcus pneumoniae infection. Infect. Immun. 69, 6718-6724. doi: 10.1128/IAI.69.11.6718-6724.2001

Attali, C., Durmort, C., Vernet, T., and Di Guilmi, A. M. (2008). The interaction of Streptococcus pneumoniae with plasmin mediates transmigration across endothelial and epithelial monolayers by intercellular junction cleavage. Infect. Immun. 76, 5350-5356. doi: 10.1128/IAI.00184-08

Bai, X. H., Chen, H. J., Jiang, Y. L., Wen, Z., Huang, Y., Cheng, W., et al. (2014). Structure of pneumococcal peptidoglycan hydrolase LytB reveals insights into the bacterial cell wall remodeling and pathogenesis. J. Biol. Chem. 289, 23403-23416. doi: 10.1074/jbc.M114.579714

Balachandran, P., Brooks-Walter, A., Virolainen-Julkunen, A., Hollingshead, S. K., and Briles, D. E. (2002). Role of pneumococcal surface protein C in nasopharyngeal carriage and pneumonia and its ability to elicit protection against carriage of Streptococcus pneumoniae. Infect. Immun. 70, 2526-2534. doi: 10.1128/IAI.70.5.2526-2534.2002

Balachandran, P., Hollingshead, S. K., Paton, J. C., and Briles, D. E. (2001). The autolytic enzyme LytA of Streptococcus pneumoniae is not responsible for releasing pneumolysin. J. Bacteriol. 183, 3108-3116. doi: 10.1128/JB.183.10. 3108-3116.2001

Barocchi, M. A., Ries, J., Zogaj, X., Hemsley, C., Albiger, B., Kanth, A., et al. (2006). A pneumococcal pilus influences virulence and host inflammatory responses. Proc. Natl. Acad. Sci. U.S.A. 103, 2857-2862. doi: 10.1073/pnas.0511017103

Barthel, D., Schindler, S., and Zipfel, P. F. (2012). Plasminogen is a complement inhibitor. J. Biol. Chem. 287, 18831-18842. doi: 10.1074/jbc.M111.323287

Benton, K. A., Paton, J. C., and Briles, D. E. (1997). The hemolytic and complement-activating properties of pneumolysin do not contribute individually to virulence in a pneumococcal bacteremia model. Microb. Pathog. 23, 201-209. doi: 10.1006/mpat.1997.0150

Bergmann, S., Lang, A., Rohde, M., Agarwal, V., Rennemeier, C., Grashoff, C., et al. (2009). Integrin-linked kinase is required for vitronectin-mediated internalization of Streptococcus pneumoniae by host cells. J. Cell Sci. 122(Pt 2), 256-267. doi: 10.1242/jcs.035600

Bergmann, S., Rohde, M., Preissner, K. T., and Hammerschmidt, S. (2005). The nine residue plasminogen-binding motif of the pneumococcal enolase is 
the major cofactor of plasmin-mediated degradation of extracellular matrix, dissolution of fibrin and transmigration. Thromb. Haemost. 94, 304-311. doi: 10.1160/TH05-05-0369

Bergmann, S., Schoenen, H., and Hammerschmidt, S. (2013). The interaction between bacterial enolase and plasminogen promotes adherence of Streptococcus pneumoniae to epithelial and endothelial cells. Int. J. Med. Microbiol. 303, 452-462. doi: 10.1016/j.ijmm.2013.06.002

Bergmann, S., Wild, D., Diekmann, O., Frank, R., Bracht, D., Chhatwal, G. S., et al. (2003). Identification of a novel plasmin(ogen)-binding motif in surface displayed alpha-enolase of Streptococcus pneumoniae. Mol. Microbiol. 49, 411-423. doi: 10.1046/j.1365-2958.2003.03557.x

Bernstein, B. E., Williams, D. M., Bressi, J. C., Kuhn, P., Gelb, M. H., Blackburn, G. M., et al. (1998). A bisubstrate analog induces unexpected conformational changes in phosphoglycerate kinase from Trypanosoma brucei. J. Mol. Biol. 279, 1137-1148. doi: 10.1006/jmbi.1998.1835

Binsker, U., Kohler, T. P., Krauel, K., Kohler, S., Schwertz, H., and Hammerschmidt, S. (2015). Pneumococcal adhesins PavB and PspC are important for the interplay with human thrombospondin-1. J. Biol. Chem. 290, 14542-14555. doi: 10.1074/jbc.M114.623876

Biro, A., Rovo, Z., Papp, D., Cervenak, L., Varga, L., Fust, G., et al. (2007). Studies on the interactions between C-reactive protein and complement proteins. Immunology 121, 40-50. doi: 10.1111/j.1365-2567.2007.02535.x

Blom, A. M., Bergmann, S., Fulde, M., Riesbeck, K., and Agarwal, V. (2014). Streptococcus pneumoniae phosphoglycerate kinase is a novel complement inhibitor affecting the membrane attack complex formation. J. Biol. Chem. 289, 32499-32511. doi: 10.1074/jbc.M114.610212

Bogaert, D., Thompson, C. M., Trzcinski, K., Malley, R., and Lipsitch, M. (2010). The role of complement in innate and adaptive immunity to pneumococcal colonization and sepsis in a murine model. Vaccine 28, 681-685. doi: 10.1016/j. vaccine.2009.10.085

Brady, A. M., Calix, J. J., Yu, J., Geno, K. A., Cutter, G. R., and Nahm, M. H. (2014). Low invasiveness of pneumococcal serotype 11A is linked to ficolin-2 recognition of $\mathrm{O}$-acetylated capsule epitopes and lectin complement pathway activation. J. Infect. Dis. 210, 1155-1165. doi: 10.1093/infdis/jiu195

Braido, F., Bellotti, M., De Maria, A., Cazzola, M., and Canonica, G. W. (2008). The role of Pneumococcal vaccine. Pulm. Pharmacol. Ther. 21, 608-615. doi: 10.1016/j.pupt.2008.04.001

Braun, J. S., Novak, R., Murray, P. J., Eischen, C. M., Susin, S. A., Kroemer, G., et al. (2001). Apoptosis-inducing factor mediates microglial and neuronal apoptosis caused by pneumococcus. J. Infect. Dis. 184, 1300-1309. doi: 10.1086/324013

Briles, D. E., Hollingshead, S., Brooks-Walter, A., Nabors, G. S., Ferguson, L., Schilling, M., et al. (2000). The potential to use PspA and other pneumococcal proteins to elicit protection against pneumococcal infection. Vaccine 18, 1707-1711. doi: 10.1016/S0264-410X(99)00511-3

Brittan, J. L., Buckeridge, T. J., Finn, A., Kadioglu, A., and Jenkinson, H. F. (2012). Pneumococcal neuraminidase A: an essential upper airway colonization factor for Streptococcus pneumoniae. Mol. Oral. Microbiol. 27, 270-283. doi: 10.1111/ j.2041-1014.2012.00658.x

Brooks-Walter, A., Briles, D. E., and Hollingshead, S. K. (1999). The pspC gene of Streptococcus pneumoniae encodes a polymorphic protein, $\mathrm{PspC}$, which elicits cross-reactive antibodies to PspA and provides immunity to pneumococcal bacteremia. Infect. Immun. 67, 6533-6542.

Brouwer, M. C., Baas, F., van der Ende, A., and van de Beek, D. (2013). Genetic variation and cerebrospinal fluid levels of mannose binding lectin in pneumococcal meningitis patients. PLOS ONE 8:e65151. doi: 10.1371/journal. pone.0065151

Brown, E. J., Hosea, S. W., and Frank, M. M. (1983). The role of antibody and complement in the reticuloendothelial clearance of pneumococci from the bloodstream. Rev. Infect. Dis. 5(Suppl. 4), S797-S805. doi: 10.1093/clinids/5. supplement_4.s797

Brown, J. S., Hussell, T., Gilliland, S. M., Holden, D. W., Paton, J. C., Ehrenstein, M. R., et al. (2002). The classical pathway is the dominant complement pathway required for innate immunity to Streptococcus pneumoniae infection in mice. Proc. Natl. Acad. Sci. U.S.A. 99, 16969-16974. doi: 10.1073/pnas.012669199

Castiblanco-Valencia, M. M., Fraga, T. R., Pagotto, A. H., Serrano, S. M., Abreu, P. A., Barbosa, A. S., et al. (2016). Plasmin cleaves fibrinogen and the human complement proteins $\mathrm{C} 3 \mathrm{~b}$ and $\mathrm{C} 5$ in the presence of Leptospira interrogans proteins: a new role of LigA and LigB in invasion and complement immune evasion. Immunobiology 221, 679-689. doi: 10.1016/j.imbio.2016.01.001

Cheng, Q., Finkel, D., and Hostetter, M. K. (2000). Novel purification scheme and functions for a C3-binding protein from Streptococcus pneumoniae. Biochemistry 39, 5450-5457. doi: 10.1021/bi992157d

Croney, C. M., Nahm, M. H., Juhn, S. K., Briles, D. E., and Crain, M. J. (2013). Invasive and noninvasive Streptococcus pneumoniae capsule and surface protein diversity following the use of a conjugate vaccine. Clin. Vaccine Immunol. 20, 1711-1718. doi: 10.1128/CVI.00381-13

Crowe, J. D., Sievwright, I. K., Auld, G. C., Moore, N. R., Gow, N. A., and Booth, N. A. (2003). Candida albicans binds human plasminogen: identification of eight plasminogen-binding proteins. Mol. Microbiol. 47, 1637-1651. doi: 10. 1046/j.1365-2958.2003.03390.x

Dalia, A. B., Standish, A. J., and Weiser, J. N. (2010). Three surface exoglycosidases from Streptococcus pneumoniae, NanA, BgaA, and StrH, promote resistance to opsonophagocytic killing by human neutrophils. Infect. Immun. 78, 2108-2116. doi: 10.1128/IAI.01125-09

Dalia, A. B., and Weiser, J. N. (2011). Minimization of bacterial size allows for complement evasion and is overcome by the agglutinating effect of antibody. Cell Host Microbe 10, 486-496. doi: 10.1016/j.chom.2011.09.009

Darrieux, M., Goulart, C., Briles, D., and Leite, L. C. (2015). Current status and perspectives on protein-based pneumococcal vaccines. Crit. Rev. Microbiol. 41, 190-200. doi: 10.3109/1040841X.2013.813902

Darrieux, M., Miyaji, E. N., Ferreira, D. M., Lopes, L. M., Lopes, A. P., Ren, B., et al. (2007). Fusion proteins containing family 1 and family 2 PspA fragments elicit protection against Streptococcus pneumoniae that correlates with antibody-mediated enhancement of complement deposition. Infect. Immun. 75, 5930-5938. doi: 10.1128/IAI.00940-07

Dave, S., Brooks-Walter, A., Pangburn, M. K., and McDaniel, L. S. (2001). PspC, a pneumococcal surface protein, binds human factor H. Infect. Immun. 69, 3435-3437. doi: 10.1128/IAI.69.5.3435-3437.2001

Dave, S., Carmicle, S., Hammerschmidt, S., Pangburn, M. K., and McDaniel, L. S. (2004). Dual roles of PspC, a surface protein of Streptococcus pneumoniae, in binding human secretory IgA and factor H. J. Immunol. 173, 471-477. doi: 10.4049/jimmunol.173.1.471

De Las Rivas, B., Garcia, J. L., Lopez, R., and Garcia, P. (2002). Purification and polar localization of pneumococcal LytB, a putative endo-beta-Nacetylglucosaminidase: the chain-dispersing murein hydrolase. J. Bacteriol. 184, 4988-5000. doi: 10.1128/JB.184.18.4988-5000.2002

Dieudonne-Vatran, A., Krentz, S., Blom, A. M., Meri, S., Henriques-Normark, B., Riesbeck, K., et al. (2009). Clinical isolates of Streptococcus pneumoniae bind the complement inhibitor C4b-binding protein in a PspC allele-dependent fashion. J. Immunol. 182, 7865-7877. doi: 10.4049/jimmunol.0802376

Dobo, J., Pal, G., Cervenak, L., and Gal, P. (2016). The emerging roles of mannosebinding lectin-associated serine proteases (MASPs) in the lectin pathway of complement and beyond. Immunol. Rev. 274, 98-111. doi: 10.1111/imr.12460

Domenech, M., Ramos-Sevillano, E., Garcia, E., Moscoso, M., and Yuste, J. (2013). Biofilm formation avoids complement immunity and phagocytosis of Streptococcus pneumoniae. Infect. Immun. 81, 2606-2615. doi: 10.1128/IAI. 00491- 13

Dunkelberger, J. R., and Song, W. C. (2010). Complement and its role in innate and adaptive immune responses. Cell Res. 20, 34-50. doi: 10.1038/cr.2009.139

Ehrnthaller, C., Ignatius, A., Gebhard, F., and Huber-Lang, M. (2011). New insights of an old defense system: structure, function, and clinical relevance of the complement system. Mol. Med. 17, 317-329. doi: 10.2119/molmed.2010. 00149

Endo, Y., Takahashi, M., Iwaki, D., Ishida, Y., Nakazawa, N., Kodama, T., et al. (2012). Mice deficient in ficolin, a lectin complement pathway recognition molecule, are susceptible to Streptococcus pneumoniae infection. J. Immunol. 189, 5860-5866. doi: 10.4049/jimmunol.1200836

Esser, A. F. (1994). The membrane attack complex of complement. Assembly, structure and cytotoxic activity. Toxicology 87, 229-247. doi: 10.1016/0300483X(94)90253-4

Fearon, D. T. (1978). Regulation by membrane sialic acid of betalHdependent decay-dissociation of amplification C3 convertase of the alternative complement pathway. Proc. Natl. Acad. Sci. U.S.A. 75, 1971-1975. doi: 10.1073/ pnas.75.4.1971 
Ferreira, D. M., Darrieux, M., Silva, D. A., Leite, L. C., Ferreira, J. M. Jr., Ho, P. L., et al. (2009). Characterization of protective mucosal and systemic immune responses elicited by pneumococcal surface protein PspA and PspC nasal vaccines against a respiratory pneumococcal challenge in mice. Clin. Vaccine Immunol. 16, 636-645. doi: 10.1128/CVI.00395-08

Ferreira, D. M., Oliveira, M. L., Moreno, A. T., Ho, P. L., Briles, D. E., and Miyaji, E. N. (2010). Protection against nasal colonization with Streptococcus pneumoniae by parenteral immunization with a DNA vaccine encoding PspA (Pneumococcal surface protein A). Microb. Pathog. 48, 205-213. doi: 10.1016/j. micpath.2010.02.009

Foley, J. H., Peterson, E. A., Lei, V., Wan, L. W., Krisinger, M. J., and Conway, E. M. (2015). Interplay between fibrinolysis and complement: plasmin cleavage of iC3b modulates immune responses. J. Thromb. Haemost. 13, 610-618. doi: $10.1111 /$ jth. 12837

Fulde, M., Bernardo-Garcia, N., Rohde, M., Nachtigall, N., Frank, R., Preissner, K. T., et al. (2014). Pneumococcal phosphoglycerate kinase interacts with plasminogen and its tissue activator. Thromb. Haemost. 111, 401-416. doi: 10.1160/TH13-05-0421

Gang, T. B., Hanley, G. A., and Agrawal, A. (2015). C-reactive protein protects mice against pneumococcal infection via both phosphocholine-dependent and phosphocholine-independent mechanisms. Infect. Immun. 83, 1845-1852. doi: 10.1128/IAI.03058-14

Garcia, P., Gonzalez, M. P., Garcia, E., Lopez, R., and Garcia, J. L. (1999). LytB, a novel pneumococcal murein hydrolase essential for cell separation. Mol. Microbiol. 31, 1275-1281. doi: 10.1046/j.1365-2958.1999.01238.x

Garcia-Laorden, M. I., Rodriguez, de Castro, F., Sole-Violan, J., Payeras, A., Briones, M. L., et al. (2013). The role of mannose-binding lectin in pneumococcal infection. Eur. Respir. J. 41, 131-139. doi: 10.1183/09031936. 00174111

Geno, K. A., Gilbert, G. L., Song, J. Y., Skovsted, I. C., Klugman, K. P., Jones, C., et al. (2015). Pneumococcal capsules and their types: past, present, and future. Clin. Microbiol. Rev. 28, 871-899. doi: 10.1128/CMR.00024-15

Genschmer, K. R., Accavitti-Loper, M. A., and Briles, D. E. (2013). A modified surface killing assay (MSKA) as a functional in vitro assay for identifying protective antibodies against pneumococcal surface protein A (PspA). Vaccine 32, 39-47. doi: 10.1016/j.vaccine.2013.10.080

Gianfaldoni, C., Censini, S., Hilleringmann, M., Moschioni, M., Facciotti, C., Pansegrau, W., et al. (2007). Streptococcus pneumoniae pilus subunits protect mice against lethal challenge. Infect. Immun. 75, 1059-1062. doi: 10.1128/IAI. 01400-06

Glennie, S., Gritzfeld, J. F., Pennington, S. H., Garner-Jones, M., Coombes, N., Hopkins, M. J., et al. (2016). Modulation of nasopharyngeal innate defenses by viral coinfection predisposes individuals to experimental pneumococcal carriage. Mucosal Immunol. 9, 56-67. doi: 10.1038/mi.2015.35

Godfroid, F., Hermand, P., Verlant, V., Denoel, P., and Poolman, J. T. (2011). Preclinical evaluation of the Pht proteins as potential cross-protective pneumococcal vaccine antigens. Infect. Immun. 79, 238-245. doi: 10.1128/IAI. 00378-10

Gor, D. O., Ding, X., Briles, D. E., Jacobs, M. R., and Greenspan, N. S. (2005). Relationship between surface accessibility for PpmA, PsaA, and PspA and antibody-mediated immunity to systemic infection by Streptococcus pneumoniae. Infect. Immun. 73, 1304-1312. doi: 10.1128/IAI.73.3.1304-1312. 2005

Gosink, K. K., Mann, E. R., Guglielmo, C., Tuomanen, E. I., and Masure, H. R. (2000). Role of novel choline binding proteins in virulence of Streptococcus pneumoniae. Infect. Immun. 68, 5690-5695. doi: 10.1128/IAI.68.10.5690-5695. 2000

Goulart, C., da Silva, T. R., Rodriguez, D., Politano, W. R., Leite, L. C., and Darrieux, M. (2013). Characterization of protective immune responses induced by pneumococcal surface protein $\mathrm{A}$ in fusion with pneumolysin derivatives. PLoS ONE 8:e59605. doi: 10.1371/journal.pone.0059605

Goulart, C., Darrieux, M., Rodriguez, D., Pimenta, F. C., Brandileone, M. C., de Andrade, A. L., et al. (2011). Selection of family 1 PspA molecules capable of inducing broad-ranging cross-reactivity by complement deposition and opsonophagocytosis by murine peritoneal cells. Vaccine 29, 1634-1642. doi: 10.1016/j.vaccine.2010.12.074

Gregersen, N., and Bross, P. (2010). Protein misfolding and cellular stress: an overview. Methods Mol. Biol. 648, 3-23. doi: 10.1007/978-1-60761-756-3_1
Gross, S. R., and Kinzy, T. G. (2005). Translation elongation factor 1A is essential for regulation of the actin cytoskeleton and cell morphology. Nat. Struct. Mol. Biol. 12, 772-778. doi: 10.1038/nsmb979

Hall-Stoodley, L., Hu, F. Z., Gieseke, A., Nistico, L., Nguyen, D., Hayes, J., et al. (2006). Direct detection of bacterial biofilms on the middle-ear mucosa of children with chronic otitis media. JAMA 296, 202-211. doi: 10.1001/jama.296. 2.202

Hamel, J., Charland, N., Pineau, I., Ouellet, C., Rioux, S., Martin, D., et al. (2004). Prevention of pneumococcal disease in mice immunized with conserved surface-accessible proteins. Infect. Immun. 72, 2659-2670. doi: 10.1128/IAI.72. 5.2659-2670.2004

Henderson, B., and Martin, A. (2011). Bacterial virulence in the moonlight: multitasking bacterial moonlighting proteins are virulence determinants in infectious disease. Infect. Immun. 79, 3476-3491. doi: 10.1128/IAI.00179-11

Henderson, B., and Martin, A. (2013). Bacterial moonlighting proteins and bacterial virulence. Curr. Top. Microbiol. Immunol. 358, 155-213. doi: 10.1007/ 82_2011_188

Henderson, B., and Martin, A. C. (2014). Protein moonlighting: a new factor in biology and medicine. Biochem. Soc. Trans. 42, 1671-1678. doi: 10.1042/ BST20140273

Herbert, A. P., Makou, E., Chen, Z. A., Kerr, H., Richards, A., Rappsilber, J., et al. (2015). Complement evasion mediated by enhancement of captured factor $\mathrm{H}$ : implications for protection of self-surfaces from complement. J. Immunol. 195, 4986-4998. doi: 10.4049/jimmunol.1501388

Hernani Mde, L., Ferreira, P. C., Ferreira, D. M., Miyaji, E. N., Ho, P. L., and Oliveira, M. L. (2011). Nasal immunization of mice with Lactobacillus casei expressing the pneumococcal surface protein $\mathrm{C}$ primes the immune system and decreases pneumococcal nasopharyngeal colonization in mice. FEMS Immunol. Med. Microbiol. 62, 263-272. doi: 10.1111/j.1574-695X.2011. 00809.x

Hilleringmann, M., Ringler, P., Muller, S. A., De Angelis, G., Rappuoli, R., Ferlenghi, I., et al. (2009). Molecular architecture of Streptococcus pneumoniae TIGR4 pili. EMBO J. 28, 3921-3930. doi: 10.1038/emboj.2009.360

Hollingshead, S. K., Becker, R., and Briles, D. E. (2000). Diversity of PspA: mosaic genes and evidence for past recombination in Streptococcus pneumoniae. Infect. Immun. 68, 5889-5900. doi: 10.1128/IAI.68.10.5889-5900.2000

Hostetter, M. K. (1999). Opsonic and nonopsonic interactions of C3 with Streptococcus pneumoniae. Microb. Drug Resist. 5, 85-89. doi: 10.1089/mdr. 1999.5.85

Hyams, C., Camberlein, E., Cohen, J. M., Bax, K., and Brown, J. S. (2010a). The Streptococcus pneumoniae capsule inhibits complement activity and neutrophil phagocytosis by multiple mechanisms. Infect. Immun. 78, 704-715. doi: 10. 1128/IAI.00881-09

Hyams, C., Trzcinski, K., Camberlein, E., Weinberger, D. M., Chimalapati, S., Noursadeghi, M., et al. (2013). Streptococcus pneumoniae capsular serotype invasiveness correlates with the degree of factor $\mathrm{H}$ binding and opsonization with C3b/iC3b. Infect. Immun. 81, 354-363. doi: 10.1128/IAI.00862-12

Hyams, C., Yuste, J., Bax, K., Camberlein, E., Weiser, J. N., and Brown, J. S. (2010b). Streptococcus pneumoniae resistance to complement-mediated immunity is dependent on the capsular serotype. Infect. Immun. 78, 716-725. doi: 10.1128/ IAI.01056-09

Iannelli, F., Oggioni, M. R., and Pozzi, G. (2002). Allelic variation in the highly polymorphic locus pspC of Streptococcus pneumoniae. Gene 284, 63-71. doi: 10.1016/S0378-1119(01)00896-4

Jacobson, G. R., and Rosenbusch, J. P. (1976). Abundance and membrane association of elongation factor Tu in E. coli. Nature 261, 23-26. doi: 10.1038/ 261023a0

Janoff, E. N., Fasching, C., Orenstein, J. M., Rubins, J. B., Opstad, N. L., and Dalmasso, A. P. (1999). Killing of Streptococcus pneumoniae by capsular polysaccharide-specific polymeric IgA, complement, and phagocytes. J. Clin. Invest. 104, 1139-1147. doi: 10.1172/JCI6310

Janulczyk, R., Iannelli, F., Sjoholm, A. G., Pozzi, G., and Bjorck, L. (2000). Hic, a novel surface protein of Streptococcus pneumoniae that interferes with complement function. J. Biol. Chem. 275, 37257-37263. doi: 10.1074/jbc. M004572200

Jarva, H., Janulczyk, R., Hellwage, J., Zipfel, P. F., Bjorck, L., and Meri, S. (2002). Streptococcus pneumoniae evades complement attack and opsonophagocytosis by expressing the $\mathrm{pspC}$ locus-encoded Hic protein that binds to short consensus 
repeats 8-11 of factor H. J. Immunol. 168, 1886-1894. doi: 10.4049/jimmunol. 168.4.1886

Jarva, H., Jokiranta, T. S., Wurzner, R., and Meri, S. (2003). Complement resistance mechanisms of streptococci. Mol. Immunol. 40, 95-107. doi: 10.1016/S01615890(03)00108-1

Jeffery, C. J. (1999). Moonlighting proteins. Trends Biochem. Sci. 24, 8-11. doi: 10.1016/S0968-0004(98)01335-8

Jin, H., Agarwal, S., Agarwal, S., and Pancholi, V. (2011). Surface export of GAPDH/SDH, a glycolytic enzyme, is essential for Streptococcus pyogenes virulence. MBio 2:e00068-11. doi: 10.1128/mBio.00068-11

Johnson, M. K., Boese-Marrazzo, D., and Pierce, W. A. Jr. (1981). Effects of pneumolysin on human polymorphonuclear leukocytes and platelets. Infect. Immun. 34, 171-176.

Johnson, M. K., Geoffroy, C., and Alouf, J. E. (1980). Binding of cholesterol by sulfhydryl-activated cytolysins. Infect. Immun. 27, 97-101.

Jonak, J. (2007). Bacterial elongation factors EF-Tu, their mutants, chimeric forms, and domains: isolation and purification. J. Chromatogr. B Analyt. Technol. Biomed. Life Sci. 849, 141-153. doi: 10.1016/j.jchromb.2006.11.053

Jounblat, R., Kadioglu, A., Mitchell, T. J., and Andrew, P. W. (2003). Pneumococcal behavior and host responses during bronchopneumonia are affected differently by the cytolytic and complement-activating activities of pneumolysin. Infect. Immun. 71, 1813-1819. doi: 10.1128/IAI.71.4.1813-1819.2003

Kadioglu, A., Weiser, J. N., Paton, J. C., and Andrew, P. W. (2008). The role of Streptococcus pneumoniae virulence factors in host respiratory colonization and disease. Nat. Rev. Microbiol. 6, 288-301. doi: 10.1038/nrmicro 1871

Kamtchoua, T., Bologa, M., Hopfer, R., Neveu, D., Hu, B., Sheng, X., et al. (2013). Safety and immunogenicity of the pneumococcal pneumolysin derivative PlyD1 in a single-antigen protein vaccine candidate in adults. Vaccine 31, 327-333. doi: 10.1016/j.vaccine.2012.11.005

Kang, Y. S., Do, Y., Lee, H. K., Park, S. H., Cheong, C., Lynch, R. M., et al. (2006). A dominant complement fixation pathway for pneumococcal polysaccharides initiated by SIGN-R1 interacting with C1q. Cell 125, 47-58. doi: 10.1016/j.cell. 2006.01.046

Kaplan, M. H., and Volanakis, J. E. (1974). Interaction of C-reactive protein complexes with the complement system. I. Consumption of human complement associated with the reaction of $\mathrm{C}$-reactive protein with pneumococcal C-polysaccharide and with the choline phosphatides, lecithin and sphingomyelin. J. Immunol. 112, 2135-2147.

Kerr, A. R., Paterson, G. K., McCluskey, J., Iannelli, F., Oggioni, M. R., Pozzi, G., et al. (2006). The contribution of PspC to pneumococcal virulence varies between strains and is accomplished by both complement evasion and complement-independent mechanisms. Infect. Immun. 74, 5319-5324. doi: 10. 1128/IAI.00543-06

Kerr, A. R., Paterson, G. K., Riboldi-Tunnicliffe, A., and Mitchell, T. J. (2005). Innate immune defense against pneumococcal pneumonia requires pulmonary complement component C3. Infect. Immun. 73, 4245-4252. doi: 10.1128/IAI. 73.7.4245-4252.2005

Khan, N., Qadri, R. A., and Sehgal, D. (2015). Correlation between in vitro complement deposition and passive mouse protection of anti-pneumococcal surface protein A monoclonal antibodies. Clin. Vaccine Immunol. 22, 99-107. doi: 10.1128/CVI.00001-14

Kim, H., Hawthorne, W. J., Kang, H. J., Lee, Y. J., Hwang, J. I., Hurh, S., et al. (2015). Human thrombomodulin regulates complement activation as well as the coagulation cascade in xeno-immune response. Xenotransplantation 22, 260-272. doi: 10.1111/xen.12173

King, S. J., Hippe, K. R., and Weiser, J. N. (2006). Deglycosylation of human glycoconjugates by the sequential activities of exoglycosidases expressed by Streptococcus pneumoniae. Mol. Microbiol. 59, 961-974. doi: 10.1111/j.13652958.2005.04984.x

Kjaer, T. R., Hansen, A. G., Sorensen, U. B., Holm, A. T., Sorensen, G. L., Jensenius, J. C., et al. (2013). M-ficolin binds selectively to the capsular polysaccharides of Streptococcus pneumoniae serotypes $19 \mathrm{~B}$ and $19 \mathrm{C}$ and of a Streptococcus mitis strain. Infect. Immun. 81, 452-459. doi: 10.1128/IAI.01148-12

Kohler, S., Hallstrom, T., Singh, B., Riesbeck, K., Sparta, G., Zipfel, P. F., et al. (2015). Binding of vitronectin and Factor $\mathrm{H}$ to Hic contributes to immune evasion of Streptococcus pneumoniae serotype 3. Thromb. Haemost. 113, 125-142. doi: 10.1160/TH14-06-0561
Kumar, S., Sheokand, N., Mhadeshwar, M. A., Raje, C. I., and Raje, M. (2012). Characterization of glyceraldehyde-3-phosphate dehydrogenase as a novel transferrin receptor. Int. J. Biochem. Cell Biol. 44, 189-199. doi: 10.1016/j.biocel. 2011.10.016

Lahteenmaki, K., Kuusela, P., and Korhonen, T. K. (2001). Bacterial plasminogen activators and receptors. FEMS Microbiol. Rev. 25, 531-552. doi: 10.1111/j. 1574-6976.2001.tb00590.x

Li, D., Wei, T., Abbott, C. M., and Harrich, D. (2013). The unexpected roles of eukaryotic translation elongation factors in RNA virus replication and pathogenesis. Microbiol. Mol. Biol. Rev. 77, 253-266. doi: 10.1128/MMBR. 00059- 12

Li, J., Glover, D. T., Szalai, A. J., Hollingshead, S. K., and Briles, D. E. (2007). PspA and $\mathrm{PspC}$ minimize immune adherence and transfer of pneumococci from erythrocytes to macrophages through their effects on complement activation. Infect. Immun. 75, 5877-5885. doi: 10.1128/IAI.00839-07

Li, J., Szalai, A. J., Hollingshead, S. K., Nahm, M. H., and Briles, D. E. (2009). Antibody to the type 3 capsule facilitates immune adherence of pneumococci to erythrocytes and augments their transfer to macrophages. Infect. Immun. 77, 464-471. doi: 10.1128/IAI.00892-08

Li, Q., Li, Y. X., Douthitt, K., Stahl, G. L., Thurman, J. M., and Tong, H. H. (2012). Role of the alternative and classical complement activation pathway in complement mediated killing against Streptococcus pneumoniae colony opacity variants during acute pneumococcal otitis media in mice. Microbes Infect. 14, 1308-1318. doi: 10.1016/j.micinf.2012. 08.002

Limoli, D. H., Sladek, J. A., Fuller, L. A., Singh, A. K., and King, S. J. (2011). BgaA acts as an adhesin to mediate attachment of some pneumococcal strains to human epithelial cells. Microbiology 157(Pt 8), 2369-2381. doi: 10.1099/mic.0. 045609-0

Long, J. P., Tong, H. H., and DeMaria, T. F. (2004). Immunization with native or recombinant Streptococcus pneumoniae neuraminidase affords protection in the chinchilla otitis media model. Infect. Immun. 72, 4309-4313. doi: 10.1128/IAI. 72.7.4309-4313.2004

Lu, L., Ma, Y., and Zhang, J. R. (2006). Streptococcus pneumoniae recruits complement factor $\mathrm{H}$ through the amino terminus of CbpA. J. Biol. Chem. 281, 15464-15474. doi: 10.1074/jbc.M602404200

MacMicking, J., Xie, Q. W., and Nathan, C. (1997). Nitric oxide and macrophage function. Annu. Rev. Immunol. 15, 323-350. doi: 10.1146/annurev.immunol.15. 1.323

Madhukaran, S. P., Kishore, U., Jamil, K., Choolani, M., and Lu, J. (2015). Decidual expression and localization of human surfactant protein SP-A and SP-D, and complement protein C1q. Mol. Immunol. 66, 197-207. doi: 10.1016/j.molimm. 2015.03.001

Malley, R., Henneke, P., Morse, S. C., Cieslewicz, M. J., Lipsitch, M., Thompson, C. M., et al. (2003). Recognition of pneumolysin by Toll-like receptor 4 confers resistance to pneumococcal infection. Proc. Natl. Acad. Sci. U.S.A. 100, 1966-1971. doi: 10.1073/pnas.0435928100

Marriott, H. M., Mitchell, T. J., and Dockrell, D. H. (2008). Pneumolysin: a doubleedged sword during the host-pathogen interaction. Curr. Mol. Med. 8, 497-509. doi: 10.2174/156652408785747924

McNeela, E. A., Burke, A., Neill, D. R., Baxter, C., Fernandes, V. E., Ferreira, D., et al. (2010). Pneumolysin activates the NLRP3 inflammasome and promotes proinflammatory cytokines independently of TLR4. PLoS Pathog. 6:e1001191. doi: 10.1371/journal.ppat.1001191

Melin, M., Di Paolo, E., Tikkanen, L., Jarva, H., Neyt, C., Kayhty, H., et al. (2010). Interaction of pneumococcal histidine triad proteins with human complement. Infect. Immun. 78, 2089-2098. doi: 10.1128/IAI.00811-09

Merle, N. S., Church, S. E., Fremeaux-Bacchi, V., and Roumenina, L. T. (2015a). Complement system part I - molecular mechanisms of activation and regulation. Front. Immunol. 6:262. doi: 10.3389/fimmu.2015. 00262

Merle, N. S., Noe, R., Halbwachs-Mecarelli, L., Fremeaux-Bacchi, V., and Roumenina, L. T. (2015b). Complement system part II: role in immunity. Front. Immunol. 6:257. doi: 10.3389/fimmu.2015.00257

Mitchell, T. J., Andrew, P. W., Saunders, F. K., Smith, A. N., and Boulnois, G. J. (1991). Complement activation and antibody binding by pneumolysin via a region of the toxin homologous to a human acute-phase protein. Mol. Microbiol. 5, 1883-1888. doi: 10.1111/j.1365-2958.1991.tb00812.x 
Miyaji, E. N., Oliveira, M. L., Carvalho, E., and Ho, P. L. (2013). Serotypeindependent pneumococcal vaccines. Cell. Mol. Life Sci. 70, 3303-3326. doi: 10.1007/s00018-012-1234-8

Modun, B., and Williams, P. (1999). The staphylococcal transferrin-binding protein is a cell wall glyceraldehyde-3-phosphate dehydrogenase. Infect. Immun. 67, 1086-1092.

Moffitt, K. L., and Malley, R. (2011). Next generation pneumococcal vaccines. Curr. Opin. Immunol. 23, 407-413. doi: 10.1016/j.coi.2011.04.002

Mohan, S., Hertweck, C., Dudda, A., Hammerschmidt, S., Skerka, C., Hallstrom, T., et al. (2014). Tuf of Streptococcus pneumoniae is a surface displayed human complement regulator binding protein. Mol. Immunol. 62, 249-264. doi: 10. 1016/j.molimm.2014.06.029

Moreno, A. T., Oliveira, M. L., Ferreira, D. M., Ho, P. L., Darrieux, M., Leite, L. C., et al. (2010). Immunization of mice with single PspA fragments induces antibodies capable of mediating complement deposition on different pneumococcal strains and cross-protection. Clin. Vaccine Immunol. 17, 439-446. doi: 10.1128/CVI.00430-09

Moreno, A. T., Oliveira, M. L., Ho, P. L., Vadesilho, C. F., Palma, G. M., Ferreira, J. M., et al. (2012). Cross-reactivity of antipneumococcal surface protein C (PspC) antibodies with different strains and evaluation of inhibition of human complement factor $\mathrm{H}$ and secretory IgA binding via PspC. Clin. Vaccine Immunol. 19, 499-507. doi: 10.1128/CVI.05706-11

Mori, Y., Yamaguchi, M., Terao, Y., Hamada, S., Ooshima, T., and Kawabata, S. (2012). alpha-Enolase of Streptococcus pneumoniae induces formation of neutrophil extracellular traps. J. Biol. Chem. 287, 10472-10481. doi: 10.1074/ jbc.M111.280321

Muhlfelder, T. W., Niemetz, J., Kreutzer, D., Beebe, D., Ward, P. A., and Rosenfeld, S. I. (1979). C5 chemotactic fragment induces leukocyte production of tissue factor activity: a link between complement and coagulation. J. Clin. Invest. 63, 147-150. doi: 10.1172/JCI109269

Mukerji, R., Mirza, S., Roche, A. M., Widener, R. W., Croney, C. M., Rhee, D. K., et al. (2012). Pneumococcal surface protein A inhibits complement deposition on the pneumococcal surface by competing with the binding of C-reactive protein to cell-surface phosphocholine. J. Immunol. 189, 5327-5335. doi: 10. 4049/jimmunol.1201967

Murase, K., Morrison, K. L., Tam, P. Y., Stafford, R. L., Jurnak, F., and Weiss, G. A. (2003). EF-Tu binding peptides identified, dissected, and affinity optimized by phage display. Chem. Biol. 10, 161-168. doi: 10.1016/S1074-5521(03) 00025-5

Nel, J. G., Theron, A. J., Durandt, C., Tintinger, G. R., Pool, R., Mitchell, T. J., et al. (2016). Pneumolysin activates neutrophil extracellular trap formation. Clin. Exp. Immunol 184, 358-367. doi: 10.1111/cei.12766

Nilsson, J., and Nissen, P. (2005). Elongation factors on the ribosome. Curr. Opin. Struct. Biol. 15, 349-354. doi: 10.1016/j.sbi.2005.05.004

Ochs, M. M., Bartlett, W., Briles, D. E., Hicks, B., Jurkuvenas, A., Lau, P., et al. (2008). Vaccine-induced human antibodies to PspA augment complement C3 deposition on Streptococcus pneumoniae. Microb. Pathog. 44, 204-214. doi: 10.1016/j.micpath.2007.09.007

Ogunniyi, A. D., Grabowicz, M., Briles, D. E., Cook, J., and Paton, J. C. (2007). Development of a vaccine against invasive pneumococcal disease based on combinations of virulence proteins of Streptococcus pneumoniae. Infect. Immun. 75, 350-357. doi: 10.1128/IAI.01103-06

Ogunniyi, A. D., Grabowicz, M., Mahdi, L. K., Cook, J., Gordon, D. L., Sadlon, T. A., et al. (2009). Pneumococcal histidine triad proteins are regulated by the $\mathrm{Zn} 2+$-dependent repressor AdcR and inhibit complement deposition through the recruitment of complement factor H. FASEB J. 23, 731-738. doi: 10.1096/fj. 08- 119537

Orihuela, C. J., Mahdavi, J., Thornton, J., Mann, B., Wooldridge, K. G., Abouseada, N., et al. (2009). Laminin receptor initiates bacterial contact with the blood brain barrier in experimental meningitis models. J. Clin. Invest. 119, 1638-1646. doi: 10.1172/JCI36759

Orrskog, S., Rounioja, S., Spadafina, T., Gallotta, M., Norman, M., Hentrich, K., et al. (2012). Pilus adhesin RrgA interacts with complement receptor 3, thereby affecting macrophage function and systemic pneumococcal disease. MBio 4:e00535-12. doi: 10.1128/mBio.00535-12

Pancholi, V., and Fischetti, V. A. (1992). A major surface protein on group A streptococci is a glyceraldehyde-3-phosphate-dehydrogenase with multiple binding activity. J. Exp. Med. 176, 415-426. doi: 10.1084/jem.176.2.415
Pangburn, M. K., Schreiber, R. D., and Muller-Eberhard, H. J. (1981). Formation of the initial C3 convertase of the alternative complement pathway. Acquisition of $\mathrm{C} 3 \mathrm{~b}$-like activities by spontaneous hydrolysis of the putative thioester in native C3. J. Exp. Med. 154, 856-867. doi: 10.1084/jem.154.3.856

Pangburn, M. K., Schreiber, R. D., and Muller-Eberhard, H. J. (1983). $\mathrm{C} 3 \mathrm{~b}$ deposition during activation of the alternative complement pathway and the effect of deposition on the activating surface. J. Immunol. 131, 1930-1935.

Paterson, G. K., and Mitchell, T. J. (2006). Innate immunity and the pneumococcus. Microbiology 152(Pt 2), 285-293. doi: 10.1099/mic.0.28551-0

Paterson, G. K., and Orihuela, C. J. (2010). Pneumococci: immunology of the innate host response. Respirology 15, 1057-1063. doi: 10.1111/j.1440-1843.2010. 01814.x

Paton, J. (2011). "Vaccines against Streptococcus pneumoniae," in Vaccine Design: Innovative Approaches and Novel Strategies, eds R. Rappuoli and F. Bagnoli (Poole: Caister Academic Press), 303-327.

Paton, J. C., Rowan-Kelly, B., and Ferrante, A. (1984). Activation of human complement by the pneumococcal toxin pneumolysin. Infect. Immun. 43, 1085-1087.

Pillemer, L., Ratnoff, O. D., Blum, L., and Lepow, I. H. (1953). The inactivation of complement and its components by plasmin. J. Exp. Med. 97, 573-589. doi: $10.1084 /$ jem.97.4.573

Price, K. E., and Camilli, A. (2009). Pneumolysin localizes to the cell wall of Streptococcus pneumoniae. J. Bacteriol. 191, 2163-2168. doi: 10.1128/JB. 01489-08

Propst-Graham, K. L., Preheim, L. C., Vander Top, E. A., Snitily, M. U., and Gentry-Nielsen, M. J. (2007). Cirrhosis-induced defects in innate pulmonary defenses against Streptococcus pneumoniae. BMC Microbiol. 7:94. doi: 10.1186/ 1471-2180-7-94

Quin, L. R., Carmicle, S., Dave, S., Pangburn, M. K., Evenhuis, J. P., and McDaniel, L. S. (2005). In vivo binding of complement regulator factor $\mathrm{H}$ by Streptococcus pneumoniae. J. Infect. Dis. 192, 1996-2003. doi: 10.1086/497605

Quin, L. R., Onwubiko, C., Moore, Q. C., Mills, M. F., McDaniel, L. S., and Carmicle, S. (2007). Factor H binding to PspC of Streptococcus pneumoniae increases adherence to human cell lines in vitro and enhances invasion of mouse lungs in vivo. Infect. Immun. 75, 4082-4087. doi: 10.1128/IAI.004 74-07

Rai, P., He, F., Kwang, J., Engelward, B. P., and Chow, V. T. (2016). Pneumococcal pneumolysin induces DNA damage and cell cycle arrest. Sci. Rep. 6:22972. doi: 10.1038/srep22972

Raje, C. I., Kumar, S., Harle, A., Nanda, J. S., and Raje, M. (2007). The macrophage cell surface glyceraldehyde-3-phosphate dehydrogenase is a novel transferrin receptor. J. Biol. Chem. 282, 3252-3261. doi: 10.1074/jbc.M60832 8200

Ram, S., Sharma, A. K., Simpson, S. D., Gulati, S., McQuillen, D. P., Pangburn, M. K., et al. (1998). A novel sialic acid binding site on factor $\mathrm{H}$ mediates serum resistance of sialylated Neisseria gonorrhoeae. J. Exp. Med. 187, 743-752. doi: $10.1084 /$ jem.187.5.743

Ramos-Sevillano, E., Moscoso, M., Garcia, P., Garcia, E., and Yuste, J. (2011). Nasopharyngeal colonization and invasive disease are enhanced by the cell wall hydrolases LytB and LytC of Streptococcus pneumoniae. PLoS ONE 6:e23626. doi: 10.1371/journal.pone.0023626

Ramos-Sevillano, E., Rodriguez-Sosa, C., Diez-Martinez, R., Gimenez, M. J., Olmedillas, E., Garcia, P., et al. (2012). Macrolides and beta-lactam antibiotics enhance C3b deposition on the surface of multidrug-resistant Streptococcus pneumoniae strains by a LytA autolysin-dependent mechanism. Antimicrob. Agents Chemother. 56, 5534-5540. doi: 10.1128/AAC.01470-12

Ramos-Sevillano, E., Urzainqui, A., Campuzano, S., Moscoso, M., GonzalezCamacho, F., Domenech, M., et al. (2015). Pleiotropic effects of cell wall amidase LytA on Streptococcus pneumoniae sensitivity to the host immune response. Infect. Immun. 83, 591-603. doi: 10.1128/IAI.02811-14

Rawlings, N. D., and Barrett, A. J. (1995). Evolutionary families of metallopeptidases. Methods Enzymol. 248, 183-228. doi: 10.1016/00766879(95)48015-3

Rayes, J., Roumenina, L. T., Dimitrov, J. D., Repesse, Y., Ing, M., Christophe, O., et al. (2014). The interaction between factor $H$ and VWF increases factor $H$ cofactor activity and regulates VWF prothrombotic status. Blood 123, 121-125. doi: 10.1182/blood-2013-04-495853 
Rayner, C. F., Jackson, A. D., Rutman, A., Dewar, A., Mitchell, T. J., Andrew, P. W., et al. (1995). Interaction of pneumolysin-sufficient and-deficient isogenic variants of Streptococcus pneumoniae with human respiratory mucosa. Infect. Immun. 63, 442-447.

Ren, B., Li, J., Genschmer, K., Hollingshead, S. K., and Briles, D. E. (2012). The absence of PspA or presence of antibody to PspA facilitates the complementdependent phagocytosis of pneumococci in vitro. Clin. Vaccine Immunol. 19, 1574-1582. doi: 10.1128/CVI.00393- 12

Ren, B., McCrory, M. A., Pass, C., Bullard, D. C., Ballantyne, C. M., $\mathrm{Xu}$, Y., et al. (2004a). The virulence function of Streptococcus pneumoniae surface protein A involves inhibition of complement activation and impairment of complement receptor-mediated protection. J. Immunol. 173, 7506-7512.

Ren, B., Szalai, A. J., Hollingshead, S. K., and Briles, D. E. (2004b). Effects of PspA and antibodies to PspA on activation and deposition of complement on the pneumococcal surface. Infect. Immun. 72, 114-122.

Ren, B., Szalai, A. J., Thomas, O., Hollingshead, S. K., and Briles, D. E. (2003). Both family 1 and family 2 PspA proteins can inhibit complement deposition and confer virulence to a capsular serotype 3 strain of Streptococcus pneumoniae. Infect. Immun. 71, 75-85. doi: 10.1128/IAI.71.1.75-85.2003

Rioux, S., Neyt, C., Di Paolo, E., Turpin, L., Charland, N., Labbe, S., et al. (2011). Transcriptional regulation, occurrence and putative role of the Pht family of Streptococcus pneumoniae. Microbiology 157(Pt 2), 336-348. doi: 10.1099/mic. 0.042184-0

Ritchie, G. E., Moffatt, B. E., Sim, R. B., Morgan, B. P., Dwek, R. A., and Rudd, P. M. (2002). Glycosylation and the complement system. Chem. Rev. 102, 305-320-319. doi: 10.1021/cr990294a

Roy, S., Knox, K., Segal, S., Griffiths, D., Moore, C. E., Welsh, K. I., et al. (2002). MBL genotype and risk of invasive pneumococcal disease: a case-control study. Lancet 359, 1569-1573. doi: 10.1016/S0140-6736(02)08516-1

Rubins, J. B., Charboneau, D., Paton, J. C., Mitchell, T. J., Andrew, P. W., and Janoff, E. N. (1995). Dual function of pneumolysin in the early pathogenesis of murine pneumococcal pneumonia. J. Clin. Invest. 95, 142-150. doi: 10.1172/JCI11 7631

Rupprecht, T. A., Angele, B., Klein, M., Heesemann, J., Pfister, H. W., Botto, M., et al. (2007). Complement C1q and C3 are critical for the innate immune response to Streptococcus pneumoniae in the central nervous system. J. Immunol. 178, 1861-1869. doi: 10.4049/jimmunol.178.3.1861

Sabharwal, V., Ram, S., Figueira, M., Park, I. H., and Pelton, S. I. (2009). Role of complement in host defense against pneumococcal otitis media. Infect. Immun. 77, 1121-1127. doi: 10.1128/IAI.01148-08

Shak, J. R., Ludewick, H. P., Howery, K. E., Sakai, F., Yi, H., Harvey, R. M., et al. (2013). Novel role for the Streptococcus pneumoniae toxin pneumolysin in the assembly of biofilms. MBio 4:e00655-13. doi: 10.1128/mBio. 00655-13

Shakhnovich, E. A., King, S. J., and Weiser, J. N. (2002). Neuraminidase expressed by Streptococcus pneumoniae desialylates the lipopolysaccharide of Neisseria meningitidis and Haemophilus influenzae: a paradigm for interbacterial competition among pathogens of the human respiratory tract. Infect. Immun. 70, 7161-7164. doi: 10.1128/IAI.70.12.7161-7164.2002

Sims, P. J., Faioni, E. M., Wiedmer, T., and Shattil, S. J. (1988). Complement proteins C5b-9 cause release of membrane vesicles from the platelet surface that are enriched in the membrane receptor for coagulation factor Va and express prothrombinase activity. J. Biol. Chem. 263, 18205-18212.

Smith, B. L., and Hostetter, M. K. (2000). C3 as substrate for adhesion of Streptococcus pneumoniae. J. Infect. Dis. 182, 497-508. doi: 10.1086/31 5722

Song, J. Y., Moseley, M. A., Burton, R. L., and Nahm, M. H. (2013). Pneumococcal vaccine and opsonic pneumococcal antibody. J. Infect. Chemother. 19, 412-425. doi: 10.1007/s10156-013-0601-1

Srivastava, A., Henneke, P., Visintin, A., Morse, S. C., Martin, V., Watkins, C., et al. (2005). The apoptotic response to pneumolysin is Toll-like receptor 4 dependent and protects against pneumococcal disease. Infect. Immun. 73, 6479-6487. doi: 10.1128/IAI.73.10.6479-6487.2005

Szalai, A. J., Briles, D. E., and Volanakis, J. E. (1995). Human C-reactive protein is protective against fatal Streptococcus pneumoniae infection in transgenic mice. J. Immunol. 155, 2557-2563.
Terao, Y., Yamaguchi, M., Hamada, S., and Kawabata, S. (2006). Multifunctional glyceraldehyde-3-phosphate dehydrogenase of Streptococcus pyogenes is essential for evasion from neutrophils. J. Biol. Chem. 281, 14215-14223. doi: 10.1074/jbc.M513408200

Terrasse, R., Amoroso, A., Vernet, T., and Di Guilmi, A. M. (2015). Streptococcus pneumoniae GAPDH is released by cell lysis and interacts with peptidoglycan. PLOS ONE 10:e0125377. doi: 10.1371/journal.pone. 0125377

Terrasse, R., Tacnet-Delorme, P., Moriscot, C., Perard, J., Schoehn, G., Vernet, T., et al. (2012). Human and pneumococcal cell surface glyceraldehyde-3phosphate dehydrogenase $(\mathrm{GAPDH})$ proteins are both ligands of human C1q protein. J. Biol. Chem. 287, 42620-42633. doi: 10.1074/jbc.M112.42 3731

Tong, H. H., Blue, L. E., James, M. A., and DeMaria, T. F. (2000). Evaluation of the virulence of a Streptococcus pneumoniae neuraminidase-deficient mutant in nasopharyngeal colonization and development of otitis media in the chinchilla model. Infect. Immun. 68, 921-924. doi: 10.1128/IAI.68.2.921-924. 2000

Tong, H. H., Li, D., Chen, S., Long, J. P., and DeMaria, T. F. (2005). Immunization with recombinant Streptococcus pneumoniae neuraminidase NanA protects chinchillas against nasopharyngeal colonization. Infect. Immun. 73, 7775-7778. doi: 10.1128/IAI.73.11.7775-7778.2005

Tu, A. H., Fulgham, R. L., McCrory, M. A., Briles, D. E., and Szalai, A. J. (1999). Pneumococcal surface protein A inhibits complement activation by Streptococcus pneumoniae. Infect. Immun. 67, 4720-4724.

Varki, A., and Gagneux, P. (2012). Multifarious roles of sialic acids in immunity. Ann. N. Y. Acad. Sci. 1253, 16-36. doi: 10.1111/j.1749-6632.2012. 06517.x

Voss, S., Hallstrom, T., Saleh, M., Burchhardt, G., Pribyl, T., Singh, B., et al. (2013). The choline-binding protein $\mathrm{PspC}$ of Streptococcus pneumoniae interacts with the C-terminal heparin-binding domain of vitronectin. J. Biol. Chem. 288, 15614-15627. doi: 10.1074/jbc.M112.443507

Watford, W. T., Wright, J. R., Hester, C. G., Jiang, H., and Frank, M. M. (2001). Surfactant protein A regulates complement activation. J. Immunol. 167, 6593-6600. doi: 10.4049/jimmunol.167.11.6593

Whiting, G. C., Evans, J. T., Patel, S., and Gillespie, S. H. (2002). Purification of native alpha-enolase from Streptococcus pneumoniae that binds plasminogen and is immunogenic. J. Med. Microbiol. 51, 837-843. doi: 10.1099/0022-131751-10-837

Yother, J., and Briles, D. E. (1992). Structural properties and evolutionary relationships of PspA, a surface protein of Streptococcus pneumoniae, as revealed by sequence analysis. J. Bacteriol. 174, 601-609. doi: 10.1128/jb.174. 2.601-609.1992

Yuste, J., Botto, M., Bottoms, S. E., and Brown, J. S. (2007). Serum amyloid P aids complement-mediated immunity to Streptococcus pneumoniae. PLoS Pathog. 3:1208-1219. doi: 10.1371/journal.ppat.0030120

Yuste, J., Botto, M., Paton, J. C., Holden, D. W., and Brown, J. S. (2005). Additive inhibition of complement deposition by pneumolysin and PspA facilitates Streptococcus pneumoniae septicemia. J. Immunol. 175, 1813-1819. doi: 10. 4049/jimmunol.175.3.1813

Yuste, J., Sen, A., Truedsson, L., Jonsson, G., Tay, L. S., Hyams, C., et al. (2008). Impaired opsonization with C3b and phagocytosis of Streptococcus pneumoniae in sera from subjects with defects in the classical complement pathway. Infect. Immun. 76, 3761-3770. doi: 10.1128/IAI.002 91-08 doi: 10.1128/JB.182.20.5919-5921.2000

Zähner, D., and Hakenbeck, R. (2000). The Streptococcus pneumoniae betagalactosidase is a surface protein. J. Bacteriol. 182, 5919-5921. doi: 10.1128/jb. 182.20.5919-5921.2000

Zhang, W. M., Wang, H. F., Gao, K., Wang, C., Liu, L., and Liu, J. X. (2015). Lactobacillus reuteri glyceraldehyde-3-phosphate dehydrogenase functions in adhesion to intestinal epithelial cells. Can. J. Microbiol. 61, 373-380. doi: 10. 1139/cjm-2014-0734

Zipfel, P. F., Hallstrom, T., Hammerschmidt, S., and Skerka, C. (2008). The complement fitness factor $\mathrm{H}$ : role in human diseases and for immune escape of pathogens, like pneumococci. Vaccine 26(Suppl. 8), I67-I74. doi: 10.1016/j. vaccine.2008.11.015 
Conflict of Interest Statement: The authors declare that the research was conducted in the absence of any commercial or financial relationships that could be construed as a potential conflict of interest.

The handling Editor declared a shared affiliation, though no other collaboration, with the authors LL, TC and states that the process nevertheless met the standards of a fair and objective review.
Copyright (c) 2017 Andre, Converso, Politano, Ferraz, Ribeiro, Leite and Darrieux. This is an open-access article distributed under the terms of the Creative Commons Attribution License (CC BY). The use, distribution or reproduction in other forums is permitted, provided the original author(s) or licensor are credited and that the original publication in this journal is cited, in accordance with accepted academic practice. No use, distribution or reproduction is permitted which does not comply with these terms. 